\title{
Covalent narlaprevir- and boceprevir-derived hybrid inhibitors of SARS-CoV-2 main protease: room- temperature X-ray and neutron crystallography, binding thermodynamics, and antiviral activity
}

\section{Daniel Kneller}

Oak Ridge National Laboratory

Hui Li

Oak Ridge National Lab

Gwyndalyn Phillips

Oak Ridge National Laboratory https://orcid.org/0000-0001-5858-3825

Kevin Weiss

Oak Ridge National Laboratory https://orcid.org/0000-0002-6486-8007

Qiu Zhang

Oak Ridge National Laboratory

Mark Arnould

Oak Ridge National Lab https://orcid.org/0000-0003-0172-8311

Colleen Jonsson

University of Tennessee Health Science Center

\section{Surekha Surendranathan}

University of Tennessee Health Science Center

Jyothi Parvathareddy

University of Tennessee Health Science Center

Matthew Blakeley

Institut Laue-Langevin https://orcid.org/0000-0002-6412-4358

\section{Leighton Coates}

Oak Ridge National Laboratory https://orcid.org/0000-0003-2342-049X

John Louis

The National Institutes of Health https:// orcid.org/0000-0002-0052-1899

\section{Peter Bonnesen}

Oak Ridge National Laboratory https://orcid.org/0000-0002-1397-8281

Andrey Kovalevsky ( $\sim$ kovalevskyay@ornl.gov )

Oak Ridge National Laboratory https://orcid.org/0000-0003-4459-9142 
Article

Keywords:

Posted Date: February 11th, 2022

DOI: https://doi.org/10.21203/rs.3.rs-1318037/v1

License: (c) (i) This work is licensed under a Creative Commons Attribution 4.0 International License. Read Full License 


\section{Abstract}

The COVID-19 pandemic continues to disrupt everyday life, with constantly emerging SARS-CoV-2 variants threatening to render current vaccines ineffective. Small-molecule antivirals can provide an important therapeutic treatment option that is subject to challenges caused by the virus variants. The viral main protease $\left(\mathrm{M}^{\mathrm{pro}}\right)$ is critical for the virus replication and thus is considered an attractive drug target for specific protease inhibitors. We performed the design and characterization of three reversible covalent hybrid inhibitors $\mathrm{BBH}-1, \mathrm{BBH}-2$ and $\mathrm{NBH}-2$, whose structures were derived from those of hepatitis $\mathrm{C}$ protease inhibitors boceprevir and narlaprevir. A joint X-ray/neutron structure of the $\mathrm{M}^{\mathrm{pro} / \mathrm{BBH}-1}$ complex demonstrated that a Cys 145 thiolate reaction with the inhibitor's keto-warhead creates a

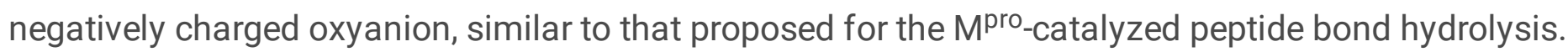
Protonation states of the ionizable residues in the $\mathrm{M}^{\text {pro }}$ active site adapt to the inhibitor, which appears to be an intrinsic property of $\mathrm{M}^{\mathrm{pro}}$. Structural comparisons of the hybrid inhibitors with PF-07321332 revealed unconventional interactions of PF-07321332 with $\mathrm{M}^{\text {pro }}$ which may explain its more favorable enthalpy of binding and consequently higher potency. $\mathrm{BBH}-1, \mathrm{BBH}-2$ and $\mathrm{NBH}-2$ demonstrated comparable antiviral properties in vitro relative to PF-07321332, making them good candidates for further design of improved antivirals.

\section{Introduction}

COronaVIrus Disease 2019 (COVID-19), caused by the novel severe acute respiratory syndrome coronavirus 2 (SARS-CoV-2), unknown to the world just over two years ago, continues to ravage the human population with wave after wave. The COVID-19 pandemic has had a catastrophic impact on human life and well-being, with over 350 million confirmed cases and over 5.6 million deaths to date globally and with millions of people suffering from long COVID complications (Sato et al., 2021; Nagu et al., 2021; Nalbandian et al., 2021). While vaccines are now readily available in some countries to protect from the disease (Meo et al., 2021), a substantial proportion of the population remains unvaccinated due to various factors, including an inability to vaccinate due to preexisting conditions or unwillingness due to personal views. This situation promotes, at least in the near future, the selection of new SARS-CoV-2 variants with multiple mutations and thus threatens the effectiveness of existing vaccines (Bian et al., 2021; Levine-Tiefenbrun et al., 2021; Wang et al., 2021). Small-molecule antiviral drugs targeting viral proteins essential for the virus replication can help alleviate this problem as the mechanism of action of such drugs would not be affected by mutations in the spike protein that would normally arise in the vaccine escape SARS-CoV-2 variants. However, repurposing of known clinical drugs for the treatment of COVID-19 has not met with much success (WHO solidarity trial consortium, 2021; Riva et al., 2020; Beigel et al., 2020). Therefore, design and development of specific antivirals against SARS-CoV-2 remains an urgent and pressing matter.

Among the initial steps in the virus replication cycle, the proteolytic function of the 3-chymotrypsin-like protease $\left(3 \mathrm{CL}^{\text {pro }}\right.$, or main protease, $\left.\mathrm{M}^{\text {pro }}\right)$ is vital for SARS-CoV-2 proliferation. After translation of the viral 
genomic mRNA by the host ribosomes, $\mathrm{M}^{\text {pro }}$ cuts the resulting large polyproteins $\mathrm{pp} 1 \mathrm{a}$ and $\mathrm{pp} 1 \mathrm{ab}$ into nonstructural proteins that assemble into the replication-transcription complex (Wu et al., 2020; Xu et al.,

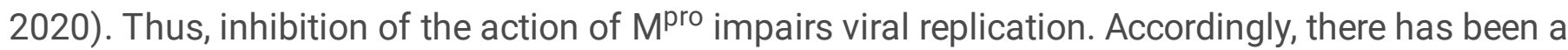
significant increase in research activity over the past two years to create specific $\mathrm{M}^{\text {pro }}$ inhibitors with potential therapeutic applications (Zhang et al., 2020; Dai et al., 2020; Ullrich \& Nitsche, 2020; Rathnayake et al., 2020; Ghosh et al., 2020; Hoffman et al., 2020; Hattori et al., 2021). Historically, design, development and clinical usage of HIV-1 and hepatitis C virus protease inhibitors (Ghosh et al., 2016; Liverton, 2019) informs us that multiple continuously improving clinical drugs will be required to overcome various challenges when treating viral infections.

$M^{\text {pro }}$ is a cysteine protease (Gorbalenya \& Snijder, 1996; Tong, 2002) that hydrolyzes peptide bonds by utilizing a noncanonical catalytic dyad comprised of Cys145 and His41 and an oxyanion hole formed by the main-chain amide NH groups of Gly143, Ser144 and Cys145. The oxyanion hole evolved to stabilize

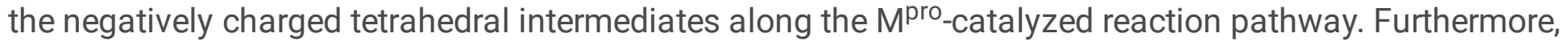
catalysis is believed to be assisted by a conserved water molecule that is hydrogen bonded to His41, His164 and Asp187, which together with Arg40 and Tyr54 comprise a partially negatively charged cluster thought to act as the third catalytic residue (Wang et al., 2020). The $\mathrm{M}^{\text {pro }}$ active site can fit substrates or inhibitors containing chemical groups at positions P5 through P $3 \otimes$ to occupy substrate binding subsites S5-S3区 (Kneller et al., 2021a; MacDonald et al., 2021). Subsites S1 and S2 are the most selective. S1 exclusively binds GIn, whereas S2 prefers medium-sized hydrophobic residues like Leu or Phe (Zhu et al., 2011; Zhang et al., 2020). Two major strategies have been employed to inhibit $\mathrm{M}^{\text {pro }}$ efficiently. On the one hand, $\mathrm{M}^{\mathrm{pro}}$ inhibitors can be noncovalent, binding to the enzyme active site only through hydrogen bonding and hydrophobic interactions. Conversely, the nucleophilic nature of Cys 145 thiolate can be exploited utilizing reactive electrophilic groups known as warheads that form an additional covalent bond with the enzyme improving inhibitor binding affinity relative to a noncovalent molecule. For example, several research groups have focused their attention on structure-based drug design of noncovalent $\mathrm{M}^{\text {pro }}$ inhibitors starting from the anti-epileptic drug perampanel (Deshmukh et al., 2021; Zhang et al., 2021), or from ML188 and ML300 previously designed to inhibit SARS-CoV-1 M ${ }^{\text {pro }}$ (Jacobs et al. 2013; Turlington et al., 2013; Kitamura et al. 2021; Han et al., 2021). We have recently performed a structure-activity relationship study (Kneller et al., 2021b) on a noncovalent compound newly discovered by highthroughput virtual screening (Clyde et al., 2021). Others have designed and evaluated a series of peptidomimetic reversible or irreversible covalent inhibitors (Konno et al., 2021; Bai et al., 2021; Yang et al., 2021), or nonpeptidic small molecules with a novel chemical scaffold (Ghosh et al., 2021).

Hepatitis $C$ virus clinical protease inhibitor boceprevir (Victrelis ${ }^{T M}$, Merck, Venkatraman, 2019) and the feline peritonitis virus protease inhibitor GC-376 (Figure 1), both peptidomimetic reversible covalent inhibitors, demonstrated effective binding and inhibition of SARS-CoV-2 $\mathrm{M}^{\text {pro }}$, and robust in vitro antiviral activity (Ma et al., 2020; Fu et al., 2020; Kneller et al. 2020a; Oerlemans et al., 2021). GC-376 is a prodrug that turns into the reactive aldehyde in aqueous solution. Not surprisingly, the chemical structures of boceprevir and GC-376 were combined to create hybrid inhibitors with improved in vitro and in vivo 
antiviral properties (Xia et al., 2021; Qiao et al., 2021). Researchers from Pfizer followed a similar strategy by additionally incorporating functional groups from compounds previously designed to inhibit SARSCoV-1 Mpro (Thanigaimalai et al., 2013; Konno et al., 2013). Pfizer's strategy ultimately resulted in the design and development of an oral drug PF-07321332 (nirmatrelvir, Figure 1, Owen et al., 2021) that has shown excellent efficacy in preventing hospitalization and death

(https://clinicaltrials.gov/ct2/show/NCT04960202). Paxlovid ${ }^{T M}$ (PF-07321332/ritonavir) was recently approved by the U.S. Food and Drug Administration for emergency use to treat COVID-19 patients. Building from our recent hepatitis C virus protease inhibitor repurposing work (Kneller et al., 2020a), we have followed an analogous strategy, working independently from and in parallel with the other research groups, to design hybrid reversible covalent inhibitors of $\mathrm{M}^{\text {pro }}$ that combine the chemical features of boceprevir and narlaprevir (Arlansa ${ }^{T M}$, R-Pharm, Russia, Arasappan et al., 2010; Isakov et al., 2016) with earlier SARS-CoV-1 $\mathrm{M}^{\text {pro }}$ inhibitors containing the widely used P1 $\mathrm{Y}$-lactam and electrophilic arylketone or nitrile functionalities as warheads (Thanigaimalai et al., 2013; Konno et al., 2013; Chuck et al., 2013). Our design logic also considered the observations and conclusions from our recent neutron structure of $\mathrm{M}^{\text {pro }}$ in complex with another hepatitis C virus protease inhibitor, telaprevir (Kneller et al., 2021c). In the

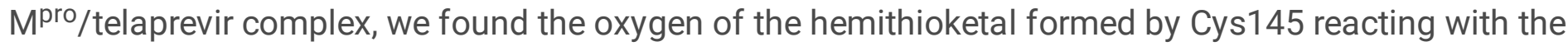
ketone warhead is protonated and makes a distorted, possibly weak, hydrogen bond with His41. Based on this observation, we hypothesized that an inhibitor's affinity might be increased by directing its warhead to form hydrogen bonding interactions with the oxyanion hole instead of His41.

Here, we present the design and characterization of three hybrid reversible covalent $\mathrm{M}^{\text {pro }}$ inhibitors named $\mathrm{BBH}-1, \mathrm{BBH}-2$ and $\mathrm{NBH}-2$ (Figure 1). To map out the atomic details of inhibitors binding to the $\mathrm{M}^{\text {pro }}$ active site, we determined a $2.2 \AA$ joint $\mathrm{X}$-ray/neutron $(\mathrm{XN})$ structure of $\mathrm{M}^{\mathrm{pro}} / \mathrm{BBH}-1$ complex and $1.8 \AA \mathrm{X}$-ray structures of $\mathrm{M}^{\mathrm{pro}} / \mathrm{BBH}-2$ and $\mathrm{M}^{\mathrm{pro}} / \mathrm{NBH}-2$ complexes at near-physiological temperature and $\mathrm{pH}$. For direct comparison, we also obtained a $2.0 \AA$ room-temperature X-ray structure of $\mathrm{M}^{\text {pro }}$ in complex with PF07321332. The $\mathrm{M}^{\mathrm{pro}} / \mathrm{BBH}-1 \mathrm{XN}$ structure captured changes of the protonation states relative to the inhibitor-free $\mathrm{M}^{\text {pro }}$ (Kneller 2020b) that could not be predicted a priori, in particular, the protonation states of four His residues located in the active site were directly visualized, revealing ionization states of His41, His163, His164 and His172. The XN structure also demonstrated that the hemithioketal generated by covalent binding of $\mathrm{BBH}-1$ to Cys145 is not protonated, its oxygen being observed as an alkoxy anion. Inhibitors BBH-2 and NBH-2 effectively inhibited $\mathrm{M}^{\text {pro }}$ in vitro, with the dissociation constants $\left(K_{\mathrm{d}}\right)$ of 26$30 \mathrm{nM}$ measured by isothermal titration calorimetry (ITC), which compare favorably with the $7 \mathrm{nM} K_{\mathrm{d}}$ for PF-07321332 $\left(K_{\mathrm{i}}=3.1 \mathrm{nM}\right.$ measured by Owen et al., 2021). Our study provides unique information on the structural and thermodynamic details of the hybrid reversible covalent inhibitors binding to SARS-CoV-2 $\mathrm{M}^{\text {pro }}$ and demonstrates that these compounds are viable for further design of specific antivirals against SARS-CoV-2.

\section{Results}




\section{Design of hybrid $\mathrm{M}^{\text {pro }}$ inhibitors}

We initiated design of hybrid inhibitors by careful examination of the chemical structures of boceprevir, narlaprevir and telaprevir and their mode of binding to $\mathrm{M}^{\text {pro }}$ based on our recent room-temperature X-ray structures (Kneller et al., 2020a). These inhibitors belong to the class of reversible covalent inhibitors, each containing an electrophilic ketone warhead that Cys145 attacks to generate the covalent hemithioketal adduct. The inhibitors chemical architectures are peptidomimetic, harboring mainly hydrophobic groups at positions P4-P1区 (P5- P1区 for narlaprevir, Figure 1). Importantly, X-ray crystallography provided evidence that these compounds have stereochemistry promoting their binding to $\mathrm{M}^{\text {pro }}$ (Kneller et al., 2020a; Ma et al., 2020; Fu et al., 2020). We have also recently shown by neutron

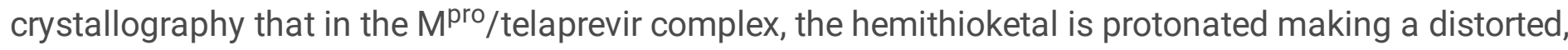
possibly weak, hydrogen bond with neutral His41. We hypothesized that directing the warhead into the oxyanion hole might benefit an inhibitor's binding affinity. We accomplished this by a) substituting the ketoamide group of boceprevir with the keto-benzothiazole moiety where the aromatic substituent is $\mathrm{P} 1 \mathrm{X}$, or b) introducing the nitrile warhead that fully eliminates the influence of a P1囚 group. Next, we substituted the hydrophobic $\mathrm{P} 1$ groups of boceprevir and narlaprevir with a $\mathrm{y}$-lactam, an established mimic of P1 GIn, found in GC-376 and earlier inhibitors of SARS-CoV-1 M ${ }^{\text {pro }}$ (Thanigaimalai et al., 2013; Konno et al., 2013; Fu et al., 2020). A P1 group must have a hydrogen bonding acceptor capability to form a strong hydrogen bond with His163 in the S1 substrate binding subsite. Recent neutron crystallographic structures of $M^{\text {pro }}$ revealed that His163 adapts from the N81-D tautomer to the protonated and positively charged state in inhibitor complexes (Kneller et al., 2021b, c). We therefore designed and synthesized the hybrid reversible covalent inhibitors BBH-1, BBH-2 and NBH-2 (Figures 1 and S1). We rescinded consideration of a narlaprevir-derived inhibitor with the keto-benzothiazole moiety due to the poor solubility of BBH-1.

\section{Adaptation of $\mathrm{M}^{\mathrm{pro}}$ active site electrostatics upon $\mathrm{BBH}-1$ binding}

To gain insight into the atomic details of a hybrid inhibitor binding to $\mathrm{M}^{\mathrm{pro}}$, we obtained a $2.2 \AA$ neutron crystallographic structure of the $\mathrm{M}^{\text {pro }} / \mathrm{BBH}-1$ complex jointly refined with $1.85 \AA$ X-ray diffraction data. Both datasets were collected at room temperature and neutral $\mathrm{pH}$ from the same deuterated protein crystal (Table S1). The joint XN structure revealed accurate locations of hydrogen atoms (observed as deuterium atoms, D), directly mapping the effect of the inhibitor binding on the active site electrostatics. For clarity, the hydrogen bonds observed in the $\mathrm{XN}$ structure are described by measuring distances between a $\mathrm{D}$ atom from a hydrogen bond donor and a heavy atom belonging to a hydrogen bond acceptor.

$\mathrm{BBH}-1$ is present in both electron and nuclear density maps (Figure 2). The maps provide evidence that the Cys 145 thiolate has reacted with the keto-warhead of $\mathrm{BBH}-1$ to form a reversible covalent hemithioketal. According to the nuclear density (Figure 3A), the hemithioketal oxygen is not protonated 
and thus is observed as an alkoxy anion $\left(\mathrm{C}^{-} \mathrm{O}^{-}\right)$. Its negatively charged oxygen is inserted into the oxyanion hole, and the charge is stabilized by a $1.9 \AA$ hydrogen bond with the main-chain amide N-D of Cys 145 . The alkoxy anion is hydrated by a water molecule, which makes a $1.8 \AA$ hydrogen bond with the charged oxygen. This water's lone electron pairs interact with the $\mathrm{P} 1 \otimes$ benzothiazole conjugated $\pi$-system through $n-\pi^{*}$ contacts with distances of 2.8-3.5 (Singh et al., 2016; Newberry \& Raines, 2017). The benzothiazole nitrogen accepts a $1.7 \AA$ hydrogen bond from another hydration water molecule that is also hydrogen bonded to the Gly143 main-chain N-D with a distance of $1.9 \AA$. The latter water molecule is part of the water network that connects benzothiazole to the Asn142 side chain and a carbonyl group of BBH-1 (Figure 2 and $3 \mathrm{~A}$ ).

The $\mathrm{y}$-lactam of the P1 group inserts into the substrate binding subsite S1 cavity formed by a stretch of residues from Phe140 to Asn142 on one side, and Glu166 and His172 on the other side (Figure 3B). The S1 subsite is further capped by Ser1区 from the second $\mathrm{M}^{\text {pro }}$ protomer, and P1 is secured by His163 at the bottom. The $y$-lactam 5-membered ring forms a conventional envelope conformation. The carbonyl oxygen makes a short 1.7 ^̊ hydrogen bond with the protonated imidazolium side chain of His163. A similar hydrogen bond was observed between the P1 uracil of a noncovalent inhibitor Mcule- 5948770040 and His163 (Kneller et al., 2021b). However, unlike the uracil group, the y-lactam doesn't make a C-H...O interaction with His172. Although the Y-lactam's amide N-D is within hydrogen bonding distance $(2.1 \AA)$ to the Glu166 carboxylate, the geometry of the contact is significantly distorted from the ideal hydrogen bond geometry. The N-D...O angle is $147^{\circ}$, and the N-D bond vector is almost perpendicular to the carboxylate plane. Moreover, the Glu166 side chain is already hydrogen bonded with His172 (2.2 $⿱ \mathrm{~A})$ and

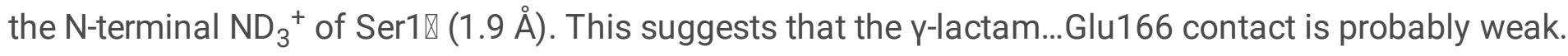
Nonetheless, the Glu166 carboxylate rotates by about $90^{\circ}$ from its observed position in the inhibitor-free $\mathrm{M}^{\mathrm{pro}}$ structure. It forms a new hydrogen bond with the neutral His172, as was observed in our other inhibitor-bound $\mathrm{M}^{\text {pro }}$ structures (Kneller et al., 2020, 2021b, c). P2, P3 and P4 groups of BBH-1 are hydrophobic and do not form hydrogen bonds with $\mathrm{M}^{\text {pro }}$. Conversely, the amide groups connecting P1/P2 and P2/P3 and the substituted urea moiety make several hydrogen bonds of 2.0-2.3 $\AA$ with the main chains of His164 and Glu166. In addition, the carbonyl of the urea moiety forms an unconventional C-H... $O$ interaction with the side chain of Gln189.

The P1区 benzothiazole is located in the substrate binding subsite S1区 flanked by Thr25, His41, Cys 44 and Met49 (Figure 3C). Because of its steric bulkiness, the benzothiazole pushes His41 away from its position in the inhibitor-free $\mathrm{M}^{\text {pro }}$ structure (Kneller et al., 2020b), forcing the His41 side chain to rotate $\sim 56^{\circ}$ around the Ca-C $\beta$ bond (Figure 3D). The His41 movement causes the catalytic water molecule $\left(\mathrm{D}_{2} \mathrm{O}_{\text {cat }}\right)$ to be ejected from the active site and His164 to become deprotonated at the Nס1 atom. A similar cascade of structural changes was previously detected in the X-ray structures of other inhibitors containing the ketobenzothiazole moiety (Hattori et al., 2021; Owen et al. 2021). Interestingly, the His41 side chain imidazole does not flip $180^{\circ}$ in the present structure and only shifts $\sim 0.4 \AA$ at $\mathrm{Ca}$ to accommodate the benzothiazole substituent, which creates an unconventional $2.1 \AA \AA$ C-H...N interaction with His164 (Figure 3C). In the published X-ray structures (Hattori et al., 2021; Owen et al. 2021), the His41 imidazole side 
chain was modeled in the flipped conformation, suggesting the formation of an $\mathrm{N}-\mathrm{H}$... N hydrogen bond with His164 (Figure S2). In both $\mathrm{M}^{\text {pro }} / \mathrm{BBH}-1$ and inhibitor-free $\mathrm{M}^{\text {pro }} \mathrm{XN}$ structures, $\mathrm{N} \varepsilon 2$ of His 164 donates its $D$ in a hydrogen bond with the Thr175 hydroxyl, which forms a hydrogen bond with the main-chain carbonyl of Asp176. This hydrogen bond is conserved in all XN structures we have determined (Kneller et al., 2020b, 2021b, c). The neutral protonation state of His172 is also maintained because it is secured by the hydrogen bond with main-chain amide N of Gly138. N81 lock Moreover, by altering the protonation states of His residues, the $\mathrm{M}^{\text {pro }}$ active site electrostatics adapts to the binding of $\mathrm{BBH}-1$. Still, it maintains the overall charge of +1 , as seen in the inhibitor-free $M^{\text {pro }}$ (Kneller et al., 2020b).

\section{Binding of inhibitors containing nitrile warhead}

To generate a detailed structural picture of the nitrile warhead-containing hybrid inhibitors $\mathrm{BBH}-2$ and $\mathrm{NBH}-2$ binding to $\mathrm{M}^{\text {pro }}$, we performed room-temperature X-ray crystallographic analysis of $\mathrm{M}^{\mathrm{pro}} / \mathrm{BBH}-2$ and $\mathrm{M}^{\mathrm{pro}} / \mathrm{NBH}-2$ complexes at $1.8 \AA$ resolution. For direct comparison, we also determined a roomtemperature X-ray structure of $\mathrm{M}^{\text {pro }}$ in complex with PF-07321332 to a resolution of $2.0 \AA$. The hydrogen bond distances in the $\mathrm{X}$-ray structures are given below with the distances measured between the heavy atoms because, unlike in the $\mathrm{M}^{\mathrm{pro}} / \mathrm{BBH}-1 \mathrm{XN}$ structure, hydrogen atoms are not observed in the electron density at such resolutions.

Both $\mathrm{BBH}-2$ and $\mathrm{NBH}-2$ bind in an essentially identical fashion to the $\mathrm{M}^{\text {pro }}$ active site. The nitrile warhead forms the covalent thioimidate conjugate with the catalytic Cys 145 and is inserted into the oxyanion hole (Figure 4). The thioimidate $\mathrm{N}$ forms a $3.0 \AA$ A hydrogen bond with the main-chain amide NH of Cys 145 but is too far from Gly 143 to form a hydrogen bond (N...N distance is $>3.6 \AA$ ) and faces the Ser144 main chain almost perpendicularly. In addition, the thioimidate $\mathrm{N}$ is hydrated by a water molecule. The interactions are likely similar to those found for the hemithioketal alkoxy anion of BBH-1. It, therefore, appears that in the case of these inhibitors only the main chain of Cys 145 , and not of Gly 143 or Ser 144 , is involved in hydrogen bonding with the covalently modified warhead. Whether the thioimidate $\mathrm{N}$ is protonated/neutral or deprotonated/negatively charged as observed for $\mathrm{BBH}-1$ hemithioketal cannot be discerned from the X-ray structure. As observed in the $\mathrm{M}^{\mathrm{pro}} / \mathrm{BBH}-1 \mathrm{XN}$ structure, $\mathrm{BBH}-2$ and $\mathrm{NBH}-2$ make several hydrogen bonds with the main chain atoms of His164 and Glu166 with the distances of 3.0-3.2 and a $2.7 \AA$ hydrogen bond with the side chain of His 163 . Of note, the thioimidate N of PF-07321332 is farther away from Cys145 main-chain amide $\mathrm{N}$ at $3.4 \AA$, but its $\mathrm{P} 1$ group and the amide connecting P3 and P4 form slightly shorter hydrogen bonds of 2.6 and $2.8 \AA$ with His163 and Glu166, respectively, compared to those seen for $\mathrm{BBH}-2$ or NBH-2. Other interactions made by $\mathrm{BBH}-2, \mathrm{NBH}-2$ and PF-07321332 with $\mathrm{M}^{\mathrm{pro}}$ are hydrophobic except those made by the $\mathrm{P} 4 \mathrm{CF}_{3}$ group of $\mathrm{PF}-07321332$. $\mathrm{The} \mathrm{CF}_{3}$ substituent makes 2.8 and $3.2 \AA$ contacts with the main-chain carbonyl oxygens of Glu166 and Thr190. Such F...O interactions have previously been characterized in small-molecule compounds as attractive multipolar interactions (Xi et al., 2018).

We have previously demonstrated (Kneller et al., 2020a, 2020c) that the active site cavity of $M^{\text {pro }}$ exhibits a significant degree of conformational plasticity and malleability, which assists in the binding of 
sterically bulky inhibitors. Specifically, the most malleable regions of the active site cavity are the S2 helix (residues 46-50), S4 $\beta$-hairpin loop (residues 165-170) and S5 loop (residues 189-194). These regions can shift by as much as $2.5 \AA$ relative to their positions in the inhibitor-free structure (Kneller et al., 2020a). It is, therefore, instructive to compare the shapes active site cavities adopt in the $\mathrm{M}^{\mathrm{pro}}$ complexes reported here with that in the inhibitor-free enzyme. Accordingly, we superimposed the four studied complexes over the XN structure of inhibitor-free $\mathrm{M}^{\text {pro }}$ (Kneller 2020b). Although the overall root-mean-square deviations (RMSDs) are low, $~ 0.4 \AA$ for all structures, significant changes in the conformations of the regions directly interacting with the inhibitors are apparent (Figure 5). The $S 2$ helix and $S 4 \beta$-hairpin loop shift by as much as $2 \AA$, whereas the 55 loop moves by about $1.7 \AA$ in $\mathrm{M}^{\text {pro }} / \mathrm{BBH}-1$ to support induced fit of the inhibitor. The conformational changes are less drastic in $\mathrm{M}^{\mathrm{pro}} / \mathrm{BBH}-2$ and $\mathrm{M}^{\mathrm{pro}} / \mathrm{NBH}-2$ for the $\mathrm{S} 4 \beta$-hairpin loop $(\sim 1.7 \AA$ ) and S5 loop ( $1.5 \AA$ ) but are more pronounced for the S2 helix ( 2.5 $)$, although P2 groups are identical in these inhibitors and the P4-P5 groups of NBH-2 are sterically substantially bulkier than the tert-butyl substituent of $\mathrm{BBH}-1$ or $\mathrm{BBH}-2$. In this regard, a noteworthy observation is that in the

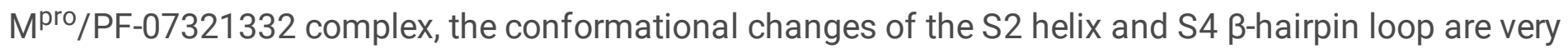
similar to those seen in the other two nitrile warhead-containing inhibitors. This finding is expected for the $\mathrm{S} 2$ helix because the $\mathrm{P} 2$ groups of the inhibitors are identical. However, the $\mathrm{P} 4 \mathrm{CF}_{3}$ group of PF-07321332 is sizably smaller than the tert-butyl moiety of $\mathrm{BBH}-2$ or the cyclohexyl group of $\mathrm{NBH}-2$. The $\mathrm{S} 4 \beta$-hairpin loop shift may partially be caused by electrostatic repulsion with the highly electronegative $\mathrm{CF}_{3}$ group. Conversely, the S5 loop moves by just $1 \AA$ in $\mathrm{M}^{\text {pro }} / \mathrm{PF}-07321332$ relative to the inhibitor-free $\mathrm{M}^{\text {pro }}$ in agreement with the reduced steric size of the $\mathrm{CF}_{3}$ group and the lack of a $\mathrm{P} 5$ group present in $\mathrm{NBH}-2$. Overall, the above structural analysis reinforces the idea that the $\mathrm{M}^{\text {pro }}$ active site cavity can accommodate various chemical groups by induced fit, especially in the subsites S4 and S5. The roomtemperature structure of the Mpro/PF-07321332 complex superimposes onto the $100 \mathrm{~K}$ structure of this complex reported previously (Owen et al. 2021) with an RMSD of $0.5 \AA$ (Figure S3). It appears, however, that the $\mathrm{M}^{\text {pro }}$ active site is more open at room temperature. The distances between the $\mathrm{S} 2 \mathrm{helix}$ and the S4 $\beta$-hairpin loop, and between the S5 loop and the S4 $\beta$-hairpin loop increase by $\sim 0.7 \AA$ in the roomtemperature structure relative to those in the $100 \mathrm{~K}$ structure. This could be due to differences in packing interactions between the unit cell types and the different data collection temperatures, but the change underscores the very flexible nature of the enzyme's active site.

\section{Binding thermodynamics of the inhibitors}

To determine the dissociation constants $\left(K_{\mathrm{d}}\right)$ and assess the binding thermodynamics of nitrile warheadcontaining inhibitors BBH-2, NBH-2 and PF-07321332, we performed isothermal titration calorimetry (ITC, Table 1 and Figure S4). We could not carry out ITC measurements for BBH-1 due to insufficient solubility of the inhibitor in buffer at the concentrations required for ITC even in the presence of $1.5 \% \mathrm{DMSO}$. BBH-2 and NBH-2 demonstrated high binding affinity to $\mathrm{M}^{\text {pro }}$, with almost identical $K_{\mathrm{d}}$ values of $0.026 \pm 0.016$ and $0.030 \pm 0.007 \mu \mathrm{M}$. Moreover, PF-07321332 binds to $\mathrm{M}^{\text {pro }}$ with several fold lower $K_{\mathrm{d}}$, demonstrating its superior binding affinity compared to the other two inhibitors and in agreement with the $K_{\mathrm{i}}$ of $0.0031 \mu \mathrm{M}$ 
reported previously (Owen et al., 2021). Binding of these inhibitors to $\mathrm{M}^{\text {pro }}$ is driven largely by enthalpy. Notably, $\triangle \mathrm{H}$ and $\triangle \mathrm{S}$ of binding for $\mathrm{BBH}-2$ and $\mathrm{NBH}-2$ are virtually identical, even though their $\mathrm{P} 4$ groups are different, and BBH-2 lacks a P5 group. This indicates that the NBH-2's P5 group has no measurable effect on its binding to $\mathrm{M}^{\text {pro }}$. The $\Delta \mathrm{H}$ of binding for $\mathrm{PF}-07321332$ is more favorable than those for $\mathrm{BBH}-2$ and $\mathrm{NBH}-2$ by about $-2 \mathrm{kcal} / \mathrm{mol}$, implying that $\mathrm{P}_{4} \mathrm{CF}_{3}$ group makes better interactions with $\mathrm{M}^{\mathrm{pro}}$ amino acid residues compared to the hydrophobic groups on the other two inhibitors. The improvement in $\Delta \mathrm{H}$ of binding for PF-07321332, however, is somewhat compensated by the less favorable $\Delta S$ of binding relative to $\mathrm{BBH}-2$ and $\mathrm{NBH}-2$. The difference in the $\Delta \mathrm{S}$ of binding could be due to greater entropy of dehydration, which is required for the bulky hydrophobic $\mathrm{P} 4$ and $\mathrm{P} 5$ groups in $\mathrm{BBH}-2$ and $\mathrm{NBH}-2$ to bind to $\mathrm{M}^{\text {pro }}$ compared to that for the small $\mathrm{CF}_{3}$ group present in PF-07321332. Nevertheless, PF-07321332 binds to the enzyme with a very small change in entropy, akin to the binding of the HL-3 series of noncovalent inhibitors (Kneller et al., 2021b). Consequently, although PF-07321332 possesses a higher binding affinity than those of $\mathrm{BBH}-2$ and $\mathrm{NBH}-2$, the interplay of $\Delta \mathrm{H}$ and $\Delta \mathrm{S}$ components manifests in the free energy of binding $(\Delta \mathrm{G})$ for PF-07321332 being only $-0.7 \mathrm{kcal} / \mathrm{mol}$ more favorable than $\Delta \mathrm{G}$ of binding for the other two inhibitors.

Table 1

Binding affinities of nitrile warhead-containing inhibitors BBH-2, NBH-2 and PF-07321332 determined by isothermal titration calorimetry $\left(K_{\mathrm{d}}\right.$ and thermodynamic parameters $\Delta \mathrm{H}, \Delta \mathrm{S}$ and $\Delta \mathrm{G}$ of binding).

\begin{tabular}{|llllll|}
\hline Compound & $\begin{array}{l}K_{\mathrm{d}} \\
\mu \mathrm{M}\end{array}$ & $\begin{array}{l}\text { Stoichiometry, } \\
\mathbf{N}\end{array}$ & $\begin{array}{l}\Delta \mathrm{H}, \\
\mathrm{kcal} \cdot \mathrm{mol}^{-1}\end{array}$ & $\begin{array}{l}\Delta \mathrm{S}, \\
\mathrm{cal} \cdot \mathrm{mol}^{-1} \cdot \mathrm{K}^{-1}\end{array}$ & $\begin{array}{l}\Delta \mathrm{G}, \\
\mathrm{kcal} \cdot \mathrm{mol}^{-1}\end{array}$ \\
\hline BBH-2 & $0.030 \pm 0.007$ & $1.000 \pm 0.005$ & $-8.74 \pm 0.08$ & 5.40 & -10.4 \\
\hline NBH-2 & $0.026 \pm 0.016$ & $0.990 \pm 0.009$ & $-8.76 \pm 0.17$ & 5.63 & -10.5 \\
\hline PF-07321332 & $0.007 \pm 0.003$ & $0.990 \pm 0.003$ & $-10.75 \pm 0.70$ & 1.57 & -11.2 \\
\hline GC-376 & $0.15 \pm 0.03^{\text {a }}$ & $0.99 \pm 0.01$ & $-6.7 \pm 0.1$ & 9.1 & -9.4 \\
\hline a ITC values for GC-376 are taken from Nashed et al., 2022. & & \\
\hline
\end{tabular}

\section{Antiviral activity}

The in vitro antiviral activity of all four compounds, BBH-1, BBH-2, NBH-2, and PF-07321332, was evaluated in Vero E6 TMRSSS cells. These cells express significant amounts of P-glycoprotein that acts as an efflux pump capable of efficiently removing these compounds from the cytoplasm (Owen et al., 2021; Boras et al., 2021). Therefore, we assessed the antiviral properties of the inhibitors in the absence and presence of CP-100356, a P-glycoprotein inhibitor. In the absence of CP-100356, BBH-1, BBH-2 and $\mathrm{NBH}-2$ inhibited viral replication rather weakly, with $\mathrm{EC}_{50} \mathrm{~S}$ in the $14-16 \mu \mathrm{M}$ range, whereas PF-07321332 showed a more potent $\mathrm{EC}_{50}$ of $0.88 \mu \mathrm{M}$ (Table 2, Figure S5). Addition of $2 \mu \mathrm{M}$ CP-100367 significantly improved the antiviral potency of all the compounds, with the $\mathrm{EC}_{50}$ values decreasing at least 10 -fold for 
BBH-1 $(1.5 \mu \mathrm{M}), \mathrm{BBH}-2(0.88 \mu \mathrm{M})$ and NBH-2 $(1.82 \mu \mathrm{M})$. In the presence of CP-100356, PF-07321332 inhibited SARS-CoV-2 replication with $\mathrm{EC}_{50}$ of $0.25 \mu \mathrm{M}$, which is consistent with the recently reported measurements (Owen et el. 2021). No cytotoxicity was detected for all four inhibitors at concentrations up to $10 \mu \mathrm{M}$.

Table 2

In vitro antiviral parameters for SARS-CoV-2 $\mathrm{M}^{\text {pro }}$ inhibitors measured in

Vero E6 TMPRSSS cells in the absence or presence of P-glycoprotein inhibitor CP-100356.

\begin{tabular}{|llll|}
\hline Compound & $E C_{50}, \mu \mathrm{M}$ & $E C_{50}, \mu \mathrm{M}$ & $C C_{50} \mu \mathrm{M}$ \\
& (without CP-100356) & (with CP-100356) & \\
\hline $\mathrm{BBH}-1$ & 16.1 & 1.5 & $>10$ \\
\hline $\mathrm{BBH}-2$ & 15.4 & 0.88 & $>10$ \\
\hline $\mathrm{NBH}-2$ & 13.9 & 1.82 & $>10$ \\
\hline $\mathrm{PF}-07321332$ & 0.88 & 0.25 & $>10$ \\
\hline
\end{tabular}

\section{Discussion}

The current design approach for specific small-molecule inhibitors of SARS-CoV-2 $\mathrm{M}^{\text {pro }}$ has yielded an orally bioavailable compound PF-07321332 (Nirmatrelvir, Paxlovid ${ }^{\mathrm{TM}}$, Pfizer Inc.), a reversible covalent peptidomimetic inhibitor that takes advantage of the nucleophilic properties of the catalytic Cys 145 thiolate and whose chemical structure combines features of boceprevir, GC-376 and other earlier inhibitors of SARS-CoV-1 $\mathrm{M}^{\text {pro }}$. Further design of novel $\mathrm{M}^{\text {pro }}$ inhibitors, including covalent and noncovalent compounds, will undoubtedly be required to battle COVID-19 and to prepare for the possibility of future coronavirus outbreaks. Improved inhibitor design should consider employing both conventional hydrogen bonds and unconventional intermolecular interactions, such as $\mathrm{C}-\mathrm{H} \cdots \mathrm{O}(\mathrm{N})$ and $\mathrm{X}-$ $H \cdots \pi$ contacts, where $X=O, N, S$, or $C$ (McConnell, 2021), with $M^{\text {pro }}$ residues. Thus, hydrogen atoms that represent about half of the total atom count in both small molecules and proteins cannot be overlooked. We have been using neutron protein crystallography to create a map of hydrogen atom positions and their movements that alter active site electrostatics due to inhibitor binding in SARS-CoV-2 M ${ }^{\text {pro }}$ (Kneller et al., 2020b, 2021b, c). This led us to the design of hybrid covalent inhibitors BBH-1, BBH-2 and NBH-2 with a 100-fold improved affinity to $\mathrm{M}^{\text {pro }}$ compared to that of boceprevir and narlaprevir (Ma et al., 2020; Fu et al., 2020; Kneller et al. 2020a), whose chemical structures were the starting points in our design approach. These inhibitors together with PF-07321332 also exhibited robust antiviral properties, inhibiting SARSCoV-2 replication in our assays at the low-to-sub $\mu \mathrm{M}$ concentrations.

The most important observations in the $\mathrm{XN}$ structure of $\mathrm{M}^{\mathrm{pro}} / \mathrm{BBH}-1$ are the protonation states and hydrogen bonding contacts visualized in the oxyanion hole and S1 substrate binding subsite. As 
expected from the mechanism of cysteine protease-catalyzed peptide bond hydrolysis, the hemithioketal oxygen of BBH-1 was found not to be protonated. Its negative electric charge is stabilized by a hydrogen bond with the main chain amide $\mathrm{N}-\mathrm{H}$ of Cys145 (Figure 3). The P1 y-lactam makes a strong hydrogen bond with His163 that becomes protonated and positively charged when $\mathrm{BBH}-1$ binds to $\mathrm{M}^{\text {pro }}$. This hydrogen bond is essential for inhibitor binding affinity, as its disruption leads to a significant loss in inhibitor potency, as was shown in our structure-activity relationship study on a noncovalent inhibitor (Kneller et al., 2021b). Similar protonation states and hydrogen bond interactions can be envisaged in the $\mathrm{M}^{\text {pro }}$ complexes with the three nitrile warhead inhibitors studied here, in which the thioimidate nitrogen would be negatively charged. Protonation of His 163 to gain a positive charge upon binding of an inhibitor irrespective of the P1 group's chemical nature is evidently an intrinsic property of this residue's side chain, a conclusion drawn based on our observations of this phenomenon in all neutron structures that we have determined so far (Kneller et al., 2020b, 2021b, c). Moreover, another remarkable property of the $M^{\text {pro }}$ active site that appears to be invariant is its ability to maintain overall +1 electric charge when inhibitors bind through switching protonation states of His41, Cys145, His163 and His164 (Table S3).

Binding of the nitrile warhead-containing inhibitors $\mathrm{BBH}-2, \mathrm{NBH}-2$ and PF-07321332 is enthalpically driven, an important property for a successful drug molecule. Although the three inhibitors are similar, the entropy of binding for the two former inhibitors is significant, whereas it is small for PF-07321332 and is substantially compensated by a more favorable enthalpy of binding. This makes PF-07321332 a superior inhibitor among the three compounds studied with ITC. This result is probably caused by substituting the bulky hydrophobic $\mathrm{P} 4 / \mathrm{P} 5$ groups of $\mathrm{BBH}-2$ and $\mathrm{NBH}-2$ with a small electronegative $\mathrm{CF}_{3}$ group that minimizes the hydrophobic effect and is also capable of forming favorable unconventional $\mathrm{F} \cdots \mathrm{O}$ interactions with $\mathrm{M}^{\text {pro }}$. Thus, the $\mathrm{CF}_{3}$ group conveys more favorable antiviral properties (Table 2) and was also shown to be beneficial for the compound's metabolic stability and pharmacokinetics (Owen et al.,

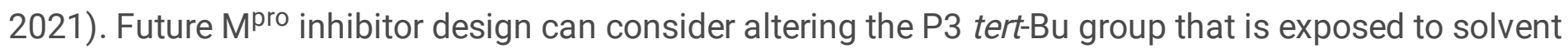
and makes no contacts with $\mathrm{M}^{\text {pro }}$ residues.

\section{Conclusion}

In summary, we designed three hybrid reversible covalent inhibitors of SARS-CoV-2 $\mathrm{M}^{\text {pro }}$ based on the chemical structures of hepatitis $\mathrm{C}$ clinical protease inhibitors narlaprevir and boceprevir and compared them to the recently FDA-approved inhibitor PF-07321332. Our study combined chemical synthesis, neutron and X-ray crystallography at nearly physiological temperature, and in vitro measurements to obtain atomic details of the inhibitors' binding to $\mathrm{M}^{\text {pro, }}$, their binding thermodynamics and antiviral potency. For the first time, we directly visualized an oxyanion bound in the catalytic site of $\mathrm{M}^{\mathrm{pro}}$, the negatively charged oxygen being generated when Cys 145 reacts with the ketone warhead of the $\mathrm{BBH}-1$ inhibitor. $\mathrm{BBH}-1, \mathrm{BBH}-2$ and $\mathrm{NBH}-2$ showed significant antiviral activity that was only slightly lower than that for PF-07221332. Our results shed new light on the atomic details of inhibitor binding to SARS-CoV-2 $\mathrm{M}^{\mathrm{pro}}$ and provide insights for future drug design. 


\section{Materials And Methods General Information}

Ni-NTA columns were purchased from Cytiva (Piscataway, New Jersey, USA). His-tagged Human Rhinovirus (HRV) 3C protease was purchased from Sigma (MilliporeSigma, St. Louis, MO). Crystallization reagents and supplies were purchased from Hampton Research (Aliso Viejo, California, USA). Crystallographic supplies for crystal mounting and X-ray and neutron diffraction data collection at room temperature were purchased from MiTeGen (Ithaca, New York, USA) and Vitrocom (Mountain Lakes, New Jersey, USA). PF-07321332 (CAS \# 2628280-40-8) was purchased from MedChemExpress (Monmouth Junction, New Jersey, USA)

\section{Synthesis of BBH-1, BBH-2, and NBH-2}

Boceprevir and narlaprevir both possess alkyl substituted 3-amino-2-oxopropanamide endgroups. It was our intent to replace those moieties with P1 fragments containing the g-lactam group and the desired nitrile or keto-benzothiazole warhead. To prepare the boceprevir-derived hybrids $\mathrm{BBH}-1$ and $\mathrm{BBH}-2$, the boceprevir fragment lacking the 3-amino-4-cyclobutyl-2-oxobutanamide moiety was utilized. This fragment, (1R,2S,5S)-3-((S)-2-(3-(tert-butyl)ureido)-3,3-dimethylbutanoyl)-6,6-dimethyl-3azabicyclo[3.1.0]hexane-2-carboxylic acid, was coupled to either $(S)$-3-((S)-2-amino-3-(benzo[d]thiazol-2yl)-3-oxopropyl)pyrrolidin-2-one (for BBH-1), or (S)-2-amino-3-((S)-2-oxopyrrolidin-3-yl)propanenitrile (for $\mathrm{BBH}-2)$, using standard amide forming methodologies employed in peptide coupling reactions. Similarly, to prepare $\mathrm{NBH}-2$, the narlaprevir fragment $(1 R, 2 S, 5 S)-3-((S)-2-(3-(1-(($ tert-

butylsulfonyl)methyl)cyclohexyl)ureido)-3,3-dimethylbutanoyl)-6,6-dimethyl-3-azabicyclo[3.1.0]hexane-2carboxylic acid was coupled with (S)-2-amino-3-((S)-2-oxopyrrolidin-3-yl)propanenitrile (see Figure S1). Details of the syntheses are described in the Supporting Information.

\section{Expression and purification of hydrogenated and partially deuterated $\mathrm{M}^{\text {pro }}$}

The SARS-CoV-2 Mpro (NSP5) gene sequence was codon optimized before being cloned into a plasmid harboring a kanamycin resistance cassette (pD451-SR, Atum, Newark, CA). The protein construct features $\mathrm{M}^{\text {pro }}$ flanked upstream by maltose binding protein (MBP) and downstream by a His6 tag (Kneller et al., 2020c). A native $\mathrm{N}$-terminus is attained during expression through an $\mathrm{M}^{\text {pro }}$ autoprocessing site corresponding to the cleavage between NSP4 and NSP5 in the viral polyprotein, SAVLQ $\downarrow$ SGFRK, where $\downarrow$ denotes the cleavage site. A native $\mathrm{C}$-terminus is produced through an HRV-3C protease cleavage site (SGVTFQ $\downarrow G P)$. Hydrogenated $\mathrm{M}^{\text {pro }}$ was expressed in Escherichia coli and purified according to the established procedures (Kneller et al., 2020c, d). Partially deuterated $\mathrm{M}^{\mathrm{pro}}$ was expressed using a bioreactor and purified as described recently (Kneller et al., 2021c). Protein yields for hydrogenated $\mathrm{M}^{\text {pro }}$ preparations averaged $\sim 3.5 \mathrm{mg}$ per $1 \mathrm{~g}$ cells and were used fresh or stored at $-30^{\circ} \mathrm{C}$. Final yield for the partially deuterated purification was $\sim 1.6 \mathrm{mg}$ per $1 \mathrm{~g}$ of cell paste and was used immediately for 
crystallization. Similar to the above strategy, a second construct was used to express and purify the wildtype $\mathrm{M}^{\text {pro }}$. Expression and purification were carried out as described previously (Kneller et al., 2021 b and Zhang et al., 2020). This second source of $\mathrm{M}^{\text {pro }}$ was used to determine the binding constants by ITC.

\section{Mpro-inhibitor complex crystallization}

Instructions for reproducing large-volume plate-shaped crystals of hydrogenated and partially deuterated $M^{\text {pro }}$ enzyme are accessible (Kneller et al., 2020d). Discovery of conditions for crystallizing $M^{\text {pro }}$ was accelerated by automated high-throughput screening at the Hauptman-Woodward Medical Research Institute (HWI) (Luft et al., 2003). Crystal aggregates of ligand-free $M^{\text {pro }}$ were reproduced locally then converted into microseeds for growing single crystals. We recently discovered that microseeded $\mathrm{M}^{\text {pro }}$ crystals grow exclusively in a cuboid morphology when co-crystallized with noncovalent ligand Mcule5948770040 and its derivatives (Kneller et al., 2021b). Cube-shaped crystals of $M^{\text {pro }}$ for current

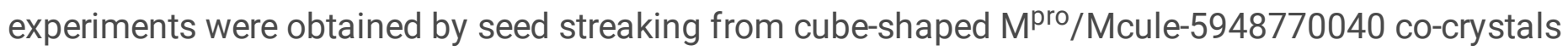
using a cat whisker or seeding tool.

Hydrogenated protein in $20 \mathrm{mM}$ Tris, $150 \mathrm{mM} \mathrm{NaCl}$, and $1 \mathrm{mM}$ TCEP (tris(2-carboxyethyl)phosphine) pH 8.0 was concentrated to $\sim 5-7 \mathrm{mg} / \mathrm{mL}$ for growing ligand-free crystals and co-crystals. Stocks of inhibitors were prepared at $50 \mathrm{mM}$ in 100\% dimethyl sulfoxide (DMSO) for crystallization purposes and stored at $-30^{\circ} \mathrm{C}$. For co-crystallization, $\mathrm{M}^{\text {pro }}$ was mixed with $\mathrm{BBH}-1, \mathrm{BBH}-2$, or $\mathrm{NBH}-2$ at $1: 5$ molar ratio and allowed to incubate at room temperature for a minimum of 30 minutes before setting up crystal trays. Crystals grown for room-temperature X-ray diffraction used sitting drop vapor diffusion methodology with 18-21\% PEG3350, $0.1 \mathrm{M}$ Bis-Tris pH 6.5 as the precipitant solution. Crystallization drops of $20 \mu \mathrm{L}$ at 1:1 ratio were seed struck with cubes as described above. Crystals appeared after 3 days of incubation at $14^{\circ} \mathrm{C}$ and continued to grow to a typical volume of $\sim 0.1 \mathrm{~mm}^{3}$. Co-crystallization attempts with PF-7321332 failed, prompting crystal soaking. A pre-grown ligand-free $\mathrm{M}^{\text {pro }}$ crystal was transferred to a different drop supplemented with PF-7321332 to a final concentration of $1.5 \mathrm{mM}$ and 3\% DMSO and allowed to soak for 10 minutes at room temperature before X-ray data collection. Crystals were mounted in MiTeGen (Ithaca, NY) room-temperature capillary setups for data collection.

For joint $X N$ crystallography, partially deuterated $\mathrm{M}^{\mathrm{pro}}$ at $10.6 \mathrm{mg} / \mathrm{mL}$ was mixed with $\mathrm{BBH}-1$ at a 1:5 molar ratio, incubated at room temperature for 30 minutes, then filtered through a $0.2 \mu \mathrm{m}$ centrifugal filter. A Hampton 9-well sandwich box was set up with $240 \mu \mathrm{L}$ drops at a 1:1 ratio of protein to $20 \%$ PEG3350, $0.1 \mathrm{M}$ Bis-Tris pH 6.5 reservoir solution. Due to the favorable 3D shape for neutron data collection, nucleation in the cube-morphology was encouraged by seed streaking. After 19 days of incubation at $10^{\circ} \mathrm{C}$, a crystal measuring $\sim 1.2 \cdot 1 \cdot 0.4 \mathrm{~mm}\left(0.5 \mathrm{~mm}^{3}\right)$ was mounted in a quartz capillary (Figure S6). The crystal was accompanied by $22 \%$ PEG3350 prepared in $100 \% \mathrm{D}_{2} \mathrm{O}$ to exchange labile hydrogens during the 2 weeks preceding neutron data collection. A separate crystal from the same drop was mounted inside a glass capillary in the same fashion for room-temperature $X$-ray data collection used in joint $X$ ray/neutron refinement. The final $\mathrm{pH}$ of the crystallization drop was measured by a microelectrode to be 
6.6 , corresponding to a neutral $\mathrm{pD}$ of $7.0(\mathrm{pD}=\mathrm{pH}+0.4)$. This $\mathrm{pD}$ is identical to previously characterized

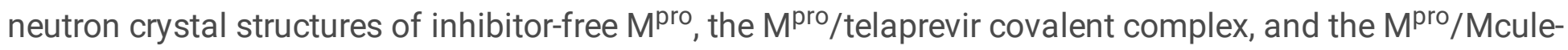
5948770040 noncovalent complex (Kneller et al., 2020b, 2021b, c).

\section{Room temperature X-ray diffraction data collection and structure refinement}

All room temperature X-ray crystallographic data was collected with a Rigaku HighFlux HomeLab instrument equipped with a MicroMax-007 HF X-ray generator, Osmic VariMax optics, and a DECTRIS Eiger R 4M hybrid photon counting detector. X-ray diffraction data were integrated using the CrysAlis Pro software suite (Rigaku Inc., The Woodlands, TX) then reduced and scaled using Aimless (Evans \& Murshudov, 2013) from the CCP4 suite (Winn et al., 2011). Structures were solved by molecular replacement using Phaser (McCoy et al., 2007) from CCP4 using PDB code 7N8C (Kneller et al., 2021b). Each model was iteratively refined with Phenix.refine from the PHENIX suite (Adams et al., 2010; Liebschner et al., 2019) and COOT (Emsley et al., 2010; Casañal et al., 2020). Geometry validation was aided by Molprobity (Chen et al., 2010). All ligand restraints were generated with eLBOW (Moriarty et al., 2009) using geometry optimized by quantum mechanical calculations in Gaussian 16 at B3LYP/6$31 \mathrm{~g}(\mathrm{~d}, \mathrm{p})$ level of theory (Frisch et al., 2016). Final data collection and refinement statistics can be found in Table S2.

\section{Neutron diffraction data collection}

Neutron diffraction was tested at room temperature on the IMAGINE (Meilleur et al., 2020; Coates et al., 2018; Meilleur et al., 2013, 2018) instrument located at the High Flux Isotope Reactor (Oak Ridge National Laboratory) using the broad bandpass functionality with neutron wavelengths between 2.8 and $10 \AA$. Neutron quasi-Laue diffraction data from a $0.5 \mathrm{~mm}^{3}$ crystal of the $\mathrm{M}^{\text {pro }} / \mathrm{BBH}-1$ complex were collected at room temperature using the LADI-III diffractometer (Blakeley et al., 2010) at the Institut Laue-Langevin (ILL) in Grenoble. A neutron wavelength range $(\Delta \lambda / \lambda=30 \%)$ of $2.80-3.75 \AA$ was used for data collection with diffraction data extending to $2.2 \AA$ resolution. The crystal was held stationary at different $\varphi$ (vertical rotation axis) for each exposure. A total of 22 images were recorded with an average exposure time of 23 hours per image from 3 different crystal orientations. The neutron data were processed using the Daresbury Laboratory LAUE suite program LAUEGEN modified to account for the cylindrical geometry of the detector (Campbell, 1995; Campbell et al., 1998). The program LSCALE (Arzt et al., 1999) was used to determine the wavelength-normalization curve using the intensities of symmetry-equivalent reflections measured at different wavelengths. No explicit absorption corrections were applied. The data were merged and scaled using SCALA (Weiss, 2001). Neutron data collection can be found in Table S1.

\section{Joint X-ray/neutron $(X N)$ refinement}

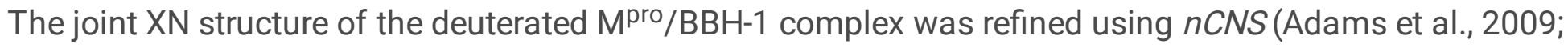
Mustyakimov \& Langan, 2007) and manual structure manipulation using COOT (Emsley et al., 2010; Casañal et al., 2020). Initial rigid-body refinement was followed by several cycles of positional, atomic 
displacement parameter, and occupancy refinement. Correctness of sidechain conformations, hydrogen bonding, and orientations of $\mathrm{D}_{2} \mathrm{O}$ water molecules in the structure was determined from $m F_{0}-D F_{C}$ difference neutron scattering length density maps. The $2 m F_{0}-D F_{C}$ and $m F_{0}-D F_{C}$ neutron scattering length density maps were then examined to determine the correct orientations of hydroxyl (Ser, Thr, Tyr), thiol (Cys), and ammonium (Lys) groups, and protonation states of the enzyme residues. The protonation states of some disordered side chains on the protein surface could not be obtained directly and remained ambiguous. Water molecules were refined as $\mathrm{D}_{2} \mathrm{O}$. Water oxygen atoms were centered on their electron density peaks, and each molecule was rotated in accordance with the neutron scattering length density maps. Hydrogen positions in the protein were modeled as deuterium atoms because the protein was partially deuterated. Occupancies of $D$ atoms were refined individually within the range of -0.56 (pure $H$ )

to 1.00 (pure $\mathrm{D}$ ) because the neutron scattering length of $\mathrm{H}$ is -0.56 times that of $\mathrm{D}$. Before depositing the neutron structure to the $\mathrm{PDB}$, coordinates of a $\mathrm{D}$ atom were split into two records corresponding to an $\mathrm{H}$ and a $D$ partially occupying the same site, both with positive partial occupancies that add up to unity. The percent $D$ at a specific site is calculated according to the following formula: $\% D=\{$ occupancy(D) + $0.56\} / 1.56$. Neutron refinement statistics can be found in Table S1.

\section{Isothermal Titration Calorimetry}

Purified $\mathrm{M}^{\text {pro }}$ was diluted from a stock solution to $60 \mu \mathrm{M}$ and dialyzed overnight at $4^{\circ} \mathrm{C}$ against $25 \mathrm{mM}$ Tris-HCl, pH 7.2, $20 \mathrm{mM} \mathrm{NaCl}$ and $1 \mathrm{mM}$ TCEP (ITC buffer). The concentration of $\mathrm{M}^{\text {pro }}$ was estimated based on its $280 \mathrm{~nm}$ absorbance. Stock solutions of inhibitors dissolved in DMSO were freshly diluted in ITC buffer prior to the titration and contained a final concentration not exceeding 1.5\% DMSO. The protein solution was also adjusted to contain the same concentration of DMSO in ITC buffer. Titrations were performed with $30 \mu \mathrm{M} \mathrm{M} \mathrm{M}^{\text {pro }}$ in the cell and $\sim 10$-fold molar excess of titrant at $28^{\circ} \mathrm{C}$ on an iTC200 microcalorimeter (Malvern Instruments Inc., Westborough, MA). Control titrations of buffer with each of the inhibitors showed a negligible response. Data were processed and plots were generated using the Origin software provided with the instrument. For competitive inhibitors that bind at only one site, the dissociation constant $\left(K_{\mathrm{d}}=1 / K_{\mathrm{a}}\right)$ is equivalent to the inhibition constant measured by enzyme kinetics $\left(K_{\mathrm{i}}\right)$.

\section{Antiviral assays}

Evaluation of antiviral activity of compounds BBH-1, BBH-2, NBH-2 and PF-7321332 was carried out in a 384-well plate with Vero E6 TMPRSSS cells as described in Bocci et al. (2020) using the USA-WA1/2020 (deposited by the Centers for Disease Control and Prevention and obtained through BEI Resources, NIAID, $\mathrm{NIH}, \mathrm{NR}-52281$ ). All activities with live virus were conducted at the UTHSC Regional Biocontainment Laboratory BSL-3. Compounds were evaluated in a dose response format starting at 10 micromolar and 6 additional 2-fold dilutions in duplicate. The cytotoxicity of compounds was tested either alone or in the presence of the P-glycoprotein inhibitor CP-100356. The antiviral activity was also assessed with the compound alone or in the presence of CP-100356 and SARS-CoV-2. CP-100356 was included at $2 \mu \mathrm{M}$ concentration to assess whether our test compounds are being effluxed out of cells due to endogenous 
expression of P-glycoprotein in the cells line, which is known for PF-7321332 (Owen et al. 2021). Following incubation for 48 hours at $5 \% \mathrm{CO}_{2}$ and $37^{\circ} \mathrm{C}$, the percent cell viability was measured with CellTiterGlo. Signals were read with an EnVision ${ }^{\circledR} 2105$ multimode plate reader. Cells alone (positive control) and cells plus virus (negative control) were set to $100 \%$ and $0 \%$ cell viability to normalize the data from the compound testing. The normalized data was used to calculate the $50 \%$ cytotoxic concentration $\left(\mathrm{CC}_{50}\right)$ and effective concentration $\left(\mathrm{EC}_{50}\right)$ using GraphPad version 9.3 .1 by plotting the log(inhibitor) vs. normalized response with a variable slope (Hill=1) (Table 2 and Figure S5).

\section{Abbreviations}

Used

SARS-CoV-2, severe acute respiratory syndrome coronavirus 2

$3 C L \mathrm{M}^{\text {pro }}$, chymotrypsin-like main protease, $\mathrm{M}^{\text {pro }}$, wild-type main protease of SARS-CoV-2.

\section{Declarations}

\section{Author contributions}

D.W.K., L.C, P.V.B., and A.K. designed the study. G.P. and Q.Z. expressed the protein. D.W.K purified the protein. K.L.W. performed protein deuteration. D.W.K. and A.K. crystallized the protein and inhibitor complexes. D.W.K., L.C. and A.K. collected X-ray data, reduced the data and refined the structures. H.L. and P.V.B. synthesized compounds. J.M.L. produced a second source of $\mathrm{M}^{\text {pro }}$ and performed ITC experiments. M.A.A. collected mass spectrometry data. C.B.J., S.S. and J.P. performed antiviral assays. M.P.B. collected and reduced neutron diffraction data. D.W.K., H.L., P.V.B., and A.K. wrote the paper with help from all co-authors.

\section{Acknowledgments}

This research used resources at the Center for Nanophase Materials Sciences, the Spallation Neutron Source and the High Flux Isotope Reactor, which are DOE Office of Science User Facilities operated by the Oak Ridge National Laboratory. The Office of Biological and Environmental Research supported research at ORNL's Center for Structural Molecular Biology (CSMB), a DOE Office of Science User Facility. This research used resources of the Spallation Neutron Source Second Target Station Project at Oak Ridge National Laboratory (ORNL). ORNL is managed by UT-Battelle LLC for DOE's Office of Science, the single largest supporter of basic research in the physical sciences in the United States. The authors thank the Institut Laue Langevin (beamline LADI-DALI) for awarded neutron beamtime. We thank Dr. Hugh M. O'Neill from ORNL for assistance during expression of the partially deuterated protein. We thank Annie Aniana from the National Institute of Diabetes and Digestive and Kidney Diseases (NIDDK) for excellent technical assistance. This work was also supported by the Intramural Research Program of NIDDK, NIH. 


\section{References}

Adams, P. D., Afonine, P. V., Bunkóczi, G., Chen, V. B., Davis, I. W., Echols, N., Headd, J. J., Hung, L. W., Kapral, G. J., Grosse-Kunstleve, R. W., McCoy, A. J., Moriarty, N. W., Oeffner, R., Read, R. J., Richardson, D. C., Richardson, J. S., Terwilliger, T. C., and Zwart, P. H. (2010) PHENIX: A comprehensive Python-based system for macromolecular structure solution. Acta Crystallogr. Sect. D Biol. Crystallogr. 66, 213-221.

Adams, P. D., Mustyakimov, M., Afonine, P. V., and Langan, P. (2009) Generalized X-ray and neutron crystallographic analysis: More accurate and complete structures for biological macromolecules. Acta Crystallogr. Sect. D Biol. Crystallogr. 65, 567-573.

Arasappan, A, Bennett, F., Bogen, S. L., Venkatraman, S., Blackman, M., Chen, K. X., Hendrata, S., Huang, Y., Huelgas, R. M., Nair, L., Padilla, A. I., Pan, W., Pike, R., Pinto, P., Ruan, S., Sannigrahi, M., Velazquez, F., Vibulbhan, B., Wu, W., Yang, W., Saksena, A. K., Girijavallabhan, V., Shih, N.-Y., Kong, J., Meng, T., Jin, Y., Wong, J., McNamara, P., Prongay, A., Madison, V., Piwinski, J. J., Cheng, K.-C., Morrison, R., Malcolm, B., Tong, X., Ralston, R., Njoroge, F. G. (2010) Discovery of narlaprevir (SCH 900518): a potent, second generation HCV NS3 serine protease inhibitor. ACS Med. Chem. Lett. 1, 64-69.

Arzt, S., Campbell, J.W., Harding, M.M., Hao, Q., Helliwell, J.R. (1999) LSCALE - the new normalization, scaling and absorption correction program in the Daresbury Laue software suite. J. Appl. Cryst. 32, 554562.

Bai, B.; Belovodskiy, A.; Hena, M.; Kandadai, A. S.; Joyce, M. A.; Saffran, H. A.; Shields, J. A.; Khan, M. B.; Arutyunova, E.; Lu, J.; Bajwa, S. K.; Hockman, D.; Fischer, C.; Lamer, T.; Vuong, W.; Belkum, M. J. van; Gu, Z.; Lin, F.; Du, Y.; Xu, J.; Rahim, M.; Young, H. S.; Vederas, J. C.; Tyrrell, D. L.; Lemieux, M. J.; Nieman, J. A. Peptidomimetic a-Acyloxymethylketone Warheads with Six-Membered Lactam P1 Glutamine Mimic: SARS-CoV-2 3CL Protease Inhibition, Coronavirus Antiviral Activity, and in Vitro Biological Stability. J. Med. Chem. 2021. https://doi.org/10.1021/ACS.JMEDCHEM.1C00616.

Beigel, J.H., Tomashek, K.M., Dodd, L.E., Mehta, A.K., Zingman, B.S., Kalil, A.C., Hohmann, E., Chu, H.Y., Luetkemeyer, A., Kline, S., Lopez de Castilla, D., Finberg, R.W., Dierberg, K., Tapson, V., Hsieh, L., Patterson, T.F., Paredes, R., Sweeney, D.A., Short, W.R., Touloumi, G., Lye, D.C., Ohmagari, N., Oh, M., Ruiz-Palacios, G.M., Benfield, T., Fätkenheuer, G., Kortepeter, M.G., Atmar, R.L., Creech, C.B., Lundgren, J., Babiker, A.G., Pett, S., Neaton, J.D., Burgess, T.H., Bonnett, T., Green, M., Makowski, M., Osinusi, A., Nayak, S., Lane, H.C. (2020) Remdesivir for the treatment of COVID-19 - final report. New Eng. J. Med. 383, 1813-1826.

Bian, L., Gao, Q., Gao, F., Wang, Q., He, Q., Wu. X., Mao, Q., Xu, M., Laing, Z. (2021) Impact of the delta variant on vaccine efficacy and response strategies. Expert Rev. Vaccines 20, 1201-1209.

Blakeley, M.P., Teixeira, S.C.M., Petit-Haertlein, I., Hazemann, I., Mitschler, A., Haertlein, M, Howard, E., Podjarny, A.D. (2010) Neutron macromolecular crystallography with LADI-III. Acta Cryst. D66, 1198-1205. 
Bocci, G., Bradfute, S. B., Ye, C., Garcia, M. J., Parvathareddy, J., Reichard, W., Surendranathan, S., Bansal, S., Bologa, C. G., Perkins, D. J., Jonsson, C. B., Sklar, L. A., Oprea, T. I. Virtual and in vitro antiviral screening revive therapeutic drugs for COVID-19. ACS. Pharmacol. Transl. Sci. 2020, 3, 1278-1292.

Boras, B., Jones, R. M., Anson, B. J., Arenson, D., Aschenbrenner, L., Bakowski, M. A., Beutler, N., Binder, J., Chen, E., Eng, H., Hammond, H., Hammond, J., Haupt, R. E., Hoffman, R., Kadar, E. P., Kania, R., Kimoto, E., Kirkpatrick, M. G., Lanyon, L., Lendy, E. K., Lillis, J. R., Logue, J., Luthra, S. A., Ma, C., Mason, S. W., McGrath, M. E., Noell, S., Obach, R. S., O’Brien, M. N., O’Connor, R., Ogilvie, K., Owen, D., Pettersson, M., Reese, M. R., Rogers, T. F., Rosales, R., Rossulek, M. I., Sathish, J. G., Shirai, N., Steppan, C., Ticehurst, M., Updyke, L. W., Weston, S., Zhu, Y., White, K. M., Garcia-Sastre, A., Wang, J., Chatterjee, A. K., Mesecar, A. D., Frieman, M. B., Anderson, A. S., Allerton, C. Preclinical characterization of an intravenous coronavirus $3 \mathrm{CL}$ protease inhibitor for the potential treatment of COVID19. Nat. Commun. 2021, 12, 6055.

Campbell, J.W. (1995) LAUEGEN, an X-windows-based program for the processing of Laue diffraction data. J. Appl. Cryst. 28, 228-236.

Campbell, J.W., Hao, Q., Harding, M.M., Nguti, N.D., Wilkinson, C. (1998) LAUEGEN version 6.0 and INTLDM. J. Appl. Cryst. 31, 496-502.

Casañal, A., Lohkamp, B., and Emsley, P. (2020) Current developments in Coot for macromolecular model building of Electron Cryo-microscopy and Crystallographic Data. Protein Sci. 29, 1069-1078.

Chen, V. B., Arendall, W. B., Headd, J. J., Keedy, D. A., Immormino, R. M., Kapral, G. J., Murray, L. W., Richardson, J. S., and Richardson, D. C. (2010) MolProbity: All-atom structure validation for macromolecular crystallography. Acta Crystallogr. Sect. D Biol. Crystallogr. 66, 12-21.

Chuck, C.-P., Chen, C., Ke, Z., Wan, D. C.-C., Chow, H.-F., Wong, K.-B. (2013) Design, synthesis and crystallographic analysis of nitrile-based broad-spectrum peptidomimetic inhibitors for coronavirus 3Clike proteases. Eur. J. Med. Chem. 59, 1-6.

A. Clyde, S. Galanie, D.W. Kneller, H. Ma, Y. Babuji, B. Blaiszik, A. Brace, T. Brettin, K. Chard, R. Chard, L. Coates, I. Foster, D. Hauner, V. Kertesz, N. Kumar, H. Lee, Z. Li, A. Merzky, J.G. Schmidt, L. Tan, M. Titov, A. Trifan, M. Turilli, H. Van Dam, S.C. Chennubhotla, S. Jha, A. Kovalevsky, A. Ramanathan, M.S. Head, R. Stevens (2021) High throughput virtual screening and validation of a SARS-CoV-2 main protease noncovalent inhibitor. J. Chem. Inform. Model., ASAP.

L. Coates, H.B. Cao, B.C. Chakoumakos, M.D. Frontzek, C. Hoffmann, A.Y. Kovalevsky, Y. Liu, F. Meilleur, A.M. dos Santos, D.A.A. Myles, X.P. Wang, F. Ye (2018) A suite-level review of the neutron single-crystal diffraction instruments at Oak Ridge National Laboratory. Rev. Sci. Instrum. 89, 092802.

Dai, W.; Zhang, B.; Jiang, X.-M.; Su, H.; Li, J.; Zhao, Y.; Xie, X.; Jin, Z.; Peng, J.; Liu, F.; Li, C.; Li, Y.; Bai, F.; Wang, H.; Cheng, X.; Cen, X.; Hu, S.; Yang, X.; Wang, J.; Liu, X.; Xiao, G.; Jiang, H.; Rao, Z.; Zhang, L.-K.; Xu, 
Y.; Yang, H.; Liu, H. Structure-based design of antiviral drug candidates targeting the SARS-CoV-2 main protease. Science 2020, 368, 1331-1335.

Deshmukh, M. G.; Ippolito, J. A.; Zhang, C.-H.; Stone, E. A.; Reilly, R. A.; Miller, S. J.; Jorgensen, W. L.; Anderson, K. S. Structure-Guided Design of a Perampanel-Derived Pharmacophore Targeting the SARSCoV-2 Main Protease. Structure 2021, 29 (8), 823-833.

Emsley, P., Lohkamp, B., Scott, W. G., and Cowtan, K. (2010) Features and development of Coot. Acta Crystallogr. Sect. D Biol. Crystallogr. 66, 486-501.

Evans, P. R., and Murshudov, G. N. (2013) How good are my data and what is the resolution? Acta Crystallogr. Sect. D Biol. Crystallogr. 69, 1204-1214.

Frisch, M. J., Trucks, G. W., Schlegel, H. B., Scuseria, G. E., Robb, M. A., Cheeseman, J. R., Scalmani, G., Barone, V., Petersson, G. A., Nakatsuji, H., Li, X., Caricato, M., Marenich, A. V., Bloino, J., Janesko, B. G., Gomperts, R., Mennucci, B., Hratchian, H. P., Ortiz, J. V., Izmaylov, A. F., Sonnenberg, J. L., Williams-Young, D., Ding, F., Lipparini, F., Egidi, F., Goings, J., Peng, B., Petrone, A., Henderson, T., Ranasinghe, D., Zakrzewski, V. G., Gao, J., Rega, N., Zheng, G., Liang, W., Hada, M., Ehara, M., Toyota, K., Fukuda, R., Hasegawa, J., Ishida, M., Nakajima, T., Honda, Y., Kitao, O., Nakai, H., Vreven, T., Throssell, K., Montgomery, J. A., J., Peralta, J. E., Ogliaro, F., Bearpark, M. J., Heyd, J. J., Brothers, E. N., Kudin, K. N., Staroverov, V. N., Keith, T. A., Kobayashi, R., Normand, J., Raghavachari, K., Rendell, A. P., Burant, J. C., lyengar, S. S., Tomasi, J., Cossi, M., Millam, J. M., Klene, M., Adamo, C., Cammi, R., Ochterski, J. W., Martin, R. L., Morokuma, K., Farkas, O., Foresman, J. B., and Fox, D. J. (2016) Gaussian 16, Revision A.03. Gaussian Inc., Wallingford, CT.

Fu, L.; Ye, F.; Feng, Y.; Yu, F.; Wang, Q.; Wu, Y.; Zhao, C.; Sun, H.; Huang, B.; Niu, P.; Song, H.; Shi, Y.; Li, X.; Tan, W.; Qi, J.; Gao, G. F. Both Boceprevir and GC376 Efficaciously Inhibit SARS-CoV-2 by Targeting Its Main Protease. Nat. Commun. 2020, 11, 4417.

Ghosh, A. K., Osswald, H. L., Prato, G. (2016) Recent progress in the development of HIV-1 protease inhibitors for the treatment of HIV-1/AIDS. J. Med. Chem. 59, 5172-5208.

Ghosh, A. K., Brindisi, M., Shahabi, D., Chapman, M. E. \& Mesecar, A. D. Drug Development and Medicinal Chemistry Efforts toward SARS-Coronavirus and Covid-19 Therapeutics. ChemMedChem 15, 907-932 (2020).

Ghosh, A. K., Raghavaiah, J., Shahabi, D., Yadav, M., Anson, B. J., Lendy, E. K., Hattori, S.-i., HigashiKuwata, N., Mitsuya, H., Mesecar A. D. (2021) Indole chloropyridinyl ester-derived SARS-CoV-2 3CLpro inhibitors: enzyme inhibition, antiviral efficacy, structure-activity relationship, and X-ray structural studies. J. Med. Chem. doi.org/10.1021/acs.jmedchem.1c01214.

Gorbalenya, A. E., Snijder, E. J. Viral cysteine proteases. Perspect. Drug Discov. Des. 1996, 6, 64-86. 
Han, S. H.; Goins, C. M.; Arya, T.; Shin, W.-J.; Maw, J.; Hooper, A.; Sonawane, D. P.; Porter, M. R.; Bannister, B. E.; Crouch, R. D.; Lindsey, A. A.; Lakatos, G.; Martinez, S. R.; Alvarado, J.; Akers, W. S.; Wang, N. S.; Jung, J. U.; Macdonald, J. D.; Stauffer, S. R. Structure-Based Optimization of ML300-Derived, Noncovalent Inhibitors Targeting the Severe Acute Respiratory Syndrome Coronavirus 3CL Protease (SARS-CoV-2 3CLpro). J. Med. Chem. 2021. https://doi.org/10.1021/acs.jmedchem.1c00598.

Hattori, S. ichiro; Higashi-Kuwata, N.; Hayashi, H.; Allu, S. R.; Raghavaiah, J.; Bulut, H.; Das, D.; Anson, B. J.; Lendy, E. K.; Takamatsu, Y.; Takamune, N.; Kishimoto, N.; Murayama, K.; Hasegawa, K.; Li, M.; Davis, D. A.; Kodama, E. N.; Yarchoan, R.; Wlodawer, A.; Misumi, S.; Mesecar, A. D.; Ghosh, A. K.; Mitsuya, H. A Small Molecule Compound with an Indole Moiety Inhibits the Main Protease of SARS-CoV-2 and Blocks Virus Replication. Nat. Commun. 2021, $12(1), 668$.

Hoffman, R. L.; Kania, R. S.; Brothers, M. A.; Davies, J. F.; Ferre, R. A.; Gajiwala, K. S.; He, M.; Hogan, R. J.; Kozminski, K.; Li, L. Y.; Lockner, J. W.; Lou, J.; Marra, M. T.; Mitchell, L. J.; Murray, B. W.; Nieman, J. A.; Noell, S.; Planken, S. P.; Rowe, T.; Ryan, K.; Smith, G. J.; Solowiej, J. E.; Steppan, C. M.; Taggart, B. Discovery of Ketone-Based Covalent Inhibitors of Coronavirus 3CL Proteases for the Potential Therapeutic Treatment of COVID-19. J. Med. Chem. 2020, 63 (21), 12725-12747.

Isakov, V., Koloda, D., Tikhonova, N., Kikalishvili, T., Krasavina, E., Lekishvili, K., Malaya, I., Ryska, M., Samsonov, M., Tolkacheva, V. Pharmacokinetics of the new hapatitis C virus NS3 protease inhibitor narlaprevir following single-dose use with or without ritonavir in patients with liver cirrhosis. Antimicrob. Agents Chemother. 2016, 60, 7098-7104.

Jacobs, J., Grum-Tokars, V., Zhou, Y., Turlington, M., Saldanha, S. A., Chase, P., Eggler, A., Dawson, E. S., Baez-Santos, Y. M., Tomar, S., Mielech, A. M., Baker, S. C., Lindsley, C. W., Hodder, P., Mesecar, A., Stauffer, S. R. Discovery, synthesis, and structure-based optimization of a series of N-(tert-butyl)-2-(N-arylamino)-2(pyridine-3-yl) acetamides (ML188) as potent noncovalent small molecule inhibitors of the severe acute respiratory syndrome coronavirus (SARS-CoV) 3CL protease. J. Med. Chem. 2013, 56, 534-546.

Kitamura, N.; Sacco, M. D.; Ma, C.; Hu, Y.; Townsend, J. A.; Meng, X.; Zhang, F.; Zhang, X.; Ba, M.; Szeto, T.; Kukuljac, A.; Marty, M. T.; Schultz, D.; Cherry, S.; Xiang, Y.; Chen, Y.; Wang, J. Expedited Approach toward the Rational Design of Noncovalent SARS-CoV-2 Main Protease Inhibitors. J. Med. Chem. 2021, 10.1021/acs.jmedchem.1c00509.

Kneller, D. W.; Galanie, S.; Phillips, G.; O’neill, H. M.; Coates, L.; Kovalevsky, A. Malleability of the SARS-CoV2 3CL Mpro Active-Site Cavity Facilitates Binding of Clinical Antivirals. Structure 2020a, 28, 1313-1320.

Kneller, D. W., Phillips, G., Weiss, K. L., Pant, S., Zhang, Q., O’Neill, H. M., Coates, L., and Kovalevsky, A. (2020b) Unusual zwitterionic catalytic site of SARS-CoV-2 main protease revealed by neutron crystallography. J. Biol. Chem. 295, 17365-17373. 
Kneller, D. W., Phillips, G., O’Neill, H. M., Jedrzejczak, R., Stols, L., Langan, P., Joachimiak, A., Coates, L., and Kovalevsky, A. (2020c) Structural plasticity of SARS-CoV-2 3CL Mpro active site cavity revealed by room temperature X-ray crystallography. Nat. Commun. 11, 3202.

Kneller, D. W., Phillips, G., Kovalevsky, A., and Coates, L. (2020d) Room-temperature neutron and X-ray data collection of 3CL Mpro from SARS-CoV-2. Acta Crystallogr. Sect. F Struct. Biol. Commun. 76, 483487.

D.W. Kneller, Q. Zhang, L. Coates, J.M. Louis, A. Kovalevsky (2021a) Michaelis-like complex of SARS-CoV2 main protease visualized by room-temperature X-ray crystallography. IUCR J. 8, 973-979.

D.W. Kneller, H. Li, S. Galanie, G. Phillips, A. Labbe, K.L. Weiss, Q. Zhang, M.A. Arnould, A. Clyde, H. Ma, A. Ramanathan, C.B. Jonsson, M.S. Head, L. Coates, J. M. Louis, P.V. Bonnesen, A. Kovalevsky (2021b) Structural, electronic and electrostatic determinants for inhibitor binding to subsites S1 and S2 in SARSCoV-2 main protease. J. Med. Chem. 64, 17366-17383.

D.W. Kneller, G. Phillips, K.L. Weiss, Q. Zhang, L. Coates, A. Kovalevsky (2021c) Direct observation of protonation state modulation in SARS-CoV-2 main protease upon inhibitor binding with neutron crystallography. J. Med. Chem. 64, 4991-5000.

Konno, S., Thanigaimalai, P., Yamamoto, T., Nakada, K., Kakiuchi, R., Takayama, K., Yamazaki, Y., Yakushiji, F., Akaji, K., Kiso, Y., Kawasaki, Y., Chen, S.-E., Freire, E., Hayashi, Y. (2013) Desing and sythesis of new tripeptide-type SARS-CoV 3CL protease inhibitors containing an elctrophilic arylketone moiety. Biooeg. Med. Chem. 21, 412-424.

Konno, S.; Kobayashi, K.; Senda, M.; Funai, Y.; Seki, Y.; Tamai, I.; Schäkel, L.; Sakata, K.; Pillaiyar, T.; Taguchi, A.; Taniguchi, A.; Gütschow, M.; Müller, C. E.; Takeuchi, K.; Hirohama, M.; Kawaguchi, A.; Kojima, M.; Senda, T.; Shirasaka, Y.; Kamitani, W.; Hayashi, Y. 3CL Protease Inhibitors with an Electrophilic Arylketone Moiety as Anti-SARS-CoV-2 Agents. J. Med. Chem. 2021.

https://doi.org/10.1021/ACS.JMEDCHEM.1C00665.

Levine-Tiefenbrun, M., Yelin, I., Alapi, H., Katz, R., Herzel, E., Kuint, J., Chodick, G., Gazit, S., Patalon, T., Kishony, R. (2021) Viral loads of delta-variant SARS-CoV-2 breakthrough infections after vaccination and booster with BNT162b2. Nat. Med. doi.org/10.1038/s41591-021-01575-4.

D. Liebschner, P. V. Afonine, M. L. Baker, G. Bunkóczi, V. B. Chen, T. I. Croll, B. Hintze, L. W. Hung, S. Jain, A. J. McCoy, N. W. Moriarty, R. D. Oeffner, B. K. Poon, M. G. Prisant, R. J. Read, J. S. Richardson, D. C. Richardson, M. D. Sammito, O. V. Sobolev, D. H. Stockwell, T. C. Terwilliger, A. G. Urzhumtsev, L. L. Videau, C. J. Williams, P. D. Adams. Macromolecular structure determination using X-rays, neutrons and electrons: recent developments in phenix. Acta Crystallogr D Struct Biol 75, 861-877 (2019).

Liverton N.J. (2019) Evolution of HCV NS3/4a Protease Inhibitors. In: Sofia M. (eds) HCV: The Journey from Discovery to a Cure. Topics in Medicinal Chemistry, vol 31. Springer, Cham. 
Luft, J. R., Collins, R. J., Fehrman, N. A., Lauricella, A. M., Veatch, C. K., and DeTitta, G. T. (2003) A deliberate approach to screening for initial crystallization conditions of biological macromolecules. $J$. Struct. Biol. 142, 170-179.

Ma, C.; Sacco, M. D.; Hurst, B.; Townsend, J. A.; Hu, Y.; Szeto, T.; Zhang, X.; Tarbet, B.; Marty, M. T.; Chen, Y.; Wang, J. Boceprevir, GC-376, and Calpain Inhibitors II, XII Inhibit SARS-CoV-2 Viral Replication by Targeting the Viral Main Protease. Cell Res. 2020, 30 (8), 678-692.

MacDonald, E. A., Frey, G., Namchuk, M. N., Harrison, S. C., Hinshaw, S. M., Windsor, I. W. Recognition of divergent viral substrates by the SARS-CoV-2 main protease. ACS. Infect. Dis. 2021, 7, 2591-2595.

McConnell, D. B. Biotin's Lessons in drug design. J. Med. Chem. 2021, 10.1021/acs.jmedchem.1c00975.

McCoy, A. J., Grosse-Kunstleve, R. W., Adams, P. D., Winn, M. D., Storoni, L. C., and Read, R. J. (2007) Phaser crystallographic software. J. Appl. Crystallogr. 40, 658-674.

F. Meilleur, P. Munshi, L. Robertson, A.D. Stoica, L. Crow, A. Kovalevsky, T. Koritsanszky, B.C. Chakoumakos, R. Blessing, D.A.A. Myles (2013) The IMAGINE instrument: first neutron protein structure and new capabilities for neutron macromolecular crystallography. Acta Cryst. D69, 2157-2160.

F. Meilleur, L. Coates, M.J. Cuneo, A. Kovalevsky, D.A.A. Myles (2018) The neutron macromolecular crystallography instruments at Oak Ridge National Laboratory: Advances, challenges, and opportunities. Crystals 8, 388.

F. Meilleur, A. Kovalevsky, D.A.A. Myles (2020) IMAGINE: The neutron protein crystallography beamline at the high flux isotope reactor. Methods Enzymol. 634, 69-85.

Meo, S. A.; Bukhari, I. A.; Akram, J.; Meo, A. S.; Klonoff, D. C. COVID-19 Vaccines: Comparison of Biological, Pharmacological Characteristics and Adverse Effects of Pfizer/BioNTech and Moderna Vaccines. Eur. Rev. Med. Pharmacol. Sci. 2021, 25 (3), 1663-1679.

Moriarty, N. W., Grosse-Kunstleve, R. W., and Adams, P. D. (2009) Electronic ligand builder and optimization workbench (eLBOW): A tool for ligand coordinate and restraint generation. Acta Crystallogr. Sect. D Biol. Crystallogr. 65, 1074-1080.

Mustyakimov, M., and Langan, P. (2007) nCNS: an open source distribution patch for CNS for macromolecular structure refinement. Los Alamos National Security, Los Alamos, NM, USA.

Nalbandian, A., Sehgal, K., Gupta, A., Madhavan, M. V., McGroder, C., Stevens, J. S., Cook, J. R., Nordvig, A. S., Shalev, D., Sehrawat, T. S., Ahluwalia, N., Bikdeli, B., Dietz, D., Der-Nigoghossian, C., Liyanage-Don, N., Rosner, G. F., Bernstein, E. J., Mohan, S., Beckley, A. A., Seres, D. S., Choueiri, T. K., Uriel, N., Ausiello, J. C., Accili, D., Freedberg, D. E., Baldwin, M., Schwartz, A., Brodie, D., Garcia, C. K., Elkind, M. S. V., Connors, J. M., Bilezikian, J. P., Landry, D. W., Wan, E. Y. (2021) Post-acute COVID-19 syndrome. Nat. Med. 27, 601615. 
Nagu, P., Parashar, A., Behl, T., Mehta, V. (2021) CNS implications of COVID-19: a comprehensive review. Rev. Neutrosci. 32, 219-234.

Nashed, N. T., Aniana, A., Ghirlando, R., Chiliveri, S. C., Louis, J. M. Modulation of the monomer-dimer equilibrium and catalytic activity of SARS-CoV-2 main protease by a transition-state analogue inhibitor. Commun. Biol. 2022, In Press.

Newberry, R. W., Raines, R. T. The n-p* interaction. Acc. Chem. Res. 2017, 50, 1838-1846.

Oerlemans, R., Riuz-Moreno, A. J., Cong, Y., Kumar, N. D., Velasco-Velazquez, M. A., Neochoritis, C. G., Smith, J., Reggiori, F., Groves, M. R., Domling, A. (2021) Repurposing the HCV NS3-4A protease drug boceprevir as COVID-19 therapeutics. RSC Med. Chem. 12, 370-379.

Owen, D. R., Allerton, C. M. N., Anderson, A. S., Aschenbrenner, L., Avery, M., Berritt, S., Boras, B., Cardin, R. D., Carlo, A., Coffman, K. J., Dantonio, A., Di, L., Eng, H., Ferre, A., Gajiwala, K. S., Gibson, S. A., Greasley, S. E., Hurst, B. L., Kadar, E. P., Kalgutkar, A. S., Lee, J. C., Lee, J., Liu, W., Mason, S. W., Noell, S., Novak, J. J., Obach, R. S., Ogilvie, K., Patel, N. C., Pettersson, M., Rai, D. K., Reese, M. R., Sammons, M. F., Sathish, J. G., Singh, R. S. P., Steppan, C. M., Stewart, A. E., Tuttle, J. B., Updyke, L., Verhoest, P. R., Wei, L., Yang, Q., Zhu, Y. An oral SARS-CoV-2 $\mathrm{M}^{\text {pro }}$ inhibitor clinical candidate for the treatment of COVID-19. Science 2021, 374, 1586-1593.

Rathnayake, A. D., Zheng, J., Kim, Y., Perera, K. D., Mackin, S., Meyerholz, D. K., Kashipathy, M. M., Battaile, K. P., Lovell, S., Perlman, S., Groutas, W. C., Chang, K.-O. 3C-like protease inhibitors block coronavirus replication in vitro and improve survival in MERS-CoV-infected mice. Science Transl. Med. 2020, 12, eabc5332.

Riva, L.; Yuan, S.; Yin, X.; Martin-Sancho, L.; Matsunaga, N.; Pache, L.; Burgstaller-Muehlbacher, S.; De Jesus, P. D.; Teriete, P.; Hull, M. V.; Chang, M. W.; Chan, J. F.-W.; Cao, J.; Poon, V. K.-M.; Herbert, K. M.; Cheng, K.; Nguyen, T.-T. H.; Rubanov, A.; Pu, Y.; Nguyen, C.; Choi, A.; Rathnasinghe, R.; Schotsaert, M.; Miorin, L.; Dejosez, M.; Zwaka, T. P.; Sit, K.-Y.; Martinez-Sobrido, L.; Liu, W.-C.; White, K. M.; Chapman, M. E.; Lendy, E. K.; Glynne, R. J.; Albrecht, R.; Ruppin, E.; Mesecar, A. D.; Johnson, J. R.; Benner, C.; Sun, R.; Schultz, P. G.; Su, A. I.; Garcia-Sastre, A.; Chatterjee, A. K.; Yuen, K.-Y.; Chanda, S. K. Discovery of SARS-CoV-2 antiviral drugs through large-scale compound repurposing. Nature 2020, 586, 113-119.

Qiao, J., Li, Y.-S., Zheng, R., Liu, F.-L., Luo, R.-H., Haung, C., Wang, Y.-F., Zhang, J., Quan, B., Shen, C., Mao, X., Liu, X., Sun, W., Yang, W., Ni, X., Wang, K., Xu, L., Duan, Z.-L., Zou, Q.-C., Zhang, H.-L., Qu, W., Long, Y.-H.P., Li, M.-H., Yang, R.-C., Liu, X., You, J., Zhou, Y., Yao, R., Li, W.-P., Liu, J.-M., Chen, P., Liu, Y., Lin, G.-F., Yang, X., Zou, J., Li, L., Hu, Y., Lu, G.-W., Li, W.-M., Wei, Y.-Q., Zheng, Y.-T., Lei, J., Yang, S. (2021) SARS-CoV-2 Mpro inhibitors with antiviral activity in transgenic mouse model. Science 371, 1374-1378.

Sato, K., Sinclair, J. E., Sadeghirad, H., Fraser, J. F., Short, K. R., Kulasinghe, A. (2021) Cardiovascular disease in SARS-CoV-2 infection. Clin. Transl. Immunol. 10, e1343. 
Singh, S. K., Mishra, K. K., Sharma, N., Das, A. Direct spectroscopic evidence for an n®p* interaction. Angew. Chem. Int. Ed. 2016, 55, 7801-7805.

Thanigaimalai, P., Konno, S., Yamamoto, T., Koiwai, Y., Taguchi, A., Takayama, K., Yakushiji, F., Akaji, K., Chen, S.-E., Naser-Tavakolian, A., Schon, A., Freire, E., Hayashi, Y. (2013) Development of potent dipeptidetype SARS-CoV $3 \mathrm{CL}$ protease inhibitors with novel P3 scaffolds: design, synthesis, biological evaluation, and docking studies. Eur. J. Med. Chem. 68, 372-384.

Tong, L. Viral proteases. Chem. Rev. 2002, 102, 4609-4626.

Turlington, M., Chun, A., Tomar, S., Eggler, A., Grum-Tokars, V., Jacobs, J., Daniels, J. S., Dawson, E., Saldanha, A., Chase, P., Baez-Santos, Y. M., Lindsley, C. W., Hodder, P., Mesecar, A. D., Stauffer, S. R. Discovery of $\mathrm{N}$-(benzo[1,2,3]triazol-1-yl)-N-(benzyl)acetamido)phenyl) carboxamides as severe acute respiratory syndrome coronavirus (SARS-CoV) 3CLpro inhibitors: identification of ML300 and noncovalent nanomolar inhibitors with an induced-fit binding. Bioorg. Med. Chem. Lett. 2013, 23, 61726177.

Ullrich, S.; Nitsche, C. The SARS-CoV-2 Main Protease as Drug Target. Bioorganic Med. Chem. Lett. 2020, $30(17), 127377$.

Venkatraman S. Discovery of Boceprevir, a Ketoamide-Derived HCV NS3 Protease Inhibitor, for Treatment of Genotype 1 Infections. In: Sofia M. (eds) HCV: The Journey from Discovery to a Cure. Topics in Medicinal Chemistry, 2019, vol 31. M. Sofia, ed. (Springer), pp. 293-315.

Wang, H., He, S., Deng, W., Zhang, Y., Li, G., Sun, J., Zhao, W., Guo, Y., Yin, Z., Li, D., and Shang, L. (2020) Comprehensive Insights into the Catalytic Mechanism of Middle East Respiratory Syndrome 3C-Like Protease and Severe Acute Respiratory Syndrome 3C-Like Protease. ACS Catal. 10, 5871-5890.

Wang, P.; Nair, M. S.; Liu, L.; Iketani, S.; Luo, Y.; Guo, Y.; Wang, M.; Yu, J.; Zhang, B.; Kwong, P. D.; Graham, B. S.; Mascola, J. R.; Chang, J. Y.; Yin, M. T.; Sobieszczyk, M.; Kyratsous, C. A.; Shapiro, L.; Sheng, Z.; Huang, Y.; Ho, D. D. Antibody Resistance of SARS-CoV-2 Variants B.1.351 and B.1.1.7. Nature 2021, 593 (7857), $130-135$.

Weiss, M.S. (2001) Global indicators of X-ray data quality. J. Appl. Cryst. 34, 130-135.

Winn, M. D., Ballard, C. C., Cowtan, K. D., Dodson, E. J., Emsley, P., Evans, P. R., Keegan, R. M., Krissinel, E. B., Leslie, A. G. W. W., McCoy, A., McNicholas, S. J., Murshudov, G. N., Pannu, N. S., Potterton, E. A., Powell, H. R., Read, R. J., Vagin, A., and Wilson, K. S. (2011) Overview of the CCP4 suite and current developments. Acta Crystallogr. Sect. D Biol. Crystallogr. 67, 235-242.

WHO Solidarity Trial Consortium, repurposed antiviral drugs for COVID-19 - interim WHO solidarity trial results. (2021) New Engl. J. Med. 384, 497-511. 
Wu, F.; Zhao, S.; Yu, B.; Chen, Y.-M.; Wang, W.; Song, Z.-G.; Hu, Y.; Tao, Z.-W.; Tian, J.-H.; Pei, Y.-Y.; Yuan, M.L.; Zhang, Y.-L.; Dai, F.-H.; Liu, Y.; Wang, Q.-M.; Zheng, J.-J.; Xu, L.; Holmes, E. C.; Zhang, Y.-Z. A New Coronavirus Associated with Human Respiratory Disease in China. Nature 2020, 579, 265-269.

Xi, N., Sun, X., Li, M., Sun, M, Xi, M. A., Zhan, Z., Yao, J., Bai, X., Wu, Y, Lao, M. Noncovalent interactions of fluroine with amide and $\mathrm{CH} 2$ groups in N-phenyl g-lactams: covalently identical fluroine atoms in nonequivalent chemical environments. J. Org. Chem. 2018, 83, 11586-11594.

Xia, Z.; Sacco, M.; Hu, Y.; Ma, C.; Meng, X.; Zhang, F.; Szeto, T.; Xiang, Y.; Chen, Y.; Wang, J. Rational Design of Hybrid SARS-CoV-2 Main Protease Inhibitors Guided by the Superimposed Cocrystal Structures with the Peptidomimetic Inhibitors GC-376, Telaprevir, and Boceprevir. ACS Pharmacol. Transl. Sci. 2021, 4 (4), $1408-1421$.

Xu, J.; Zhao, S.; Teng, T.; Abdalla, A. E.; Zhu, W.; Xie, L.; Wang, Y.; Guo, X. Systematic Comparison of Two Animal-to-Human Transmitted Human Coronaviruses: SARS-CoV-2 and SARS-CoV. Viruses 2020, 12 (2), 244.

Yang, K. S.; Ma, X. R.; Ma, Y.; Alugubelli, Y. R.; Scott, D. A.; Vatansever, E. C.; Drelich, A. K.; Sankaran, B.; Geng, Z. Z.; Blankenship, L. R.; Ward, H. E.; Sheng, Y. J.; Hsu, J. C.; Kratch, K. C.; Zhao, B.; Hayatshahi, H. S.; Liu, J.; Li, P.; Fierke, C. A.; Tseng, C. K.; Xu, S.; Liu, W. R. A Quick Route to Multiple Highly Potent SARS-CoV2 Main Protease Inhibitors. ChemMedChem 2020, 16 (6), 942-948.

Zhang, L.; Lin, D.; Sun, X.; Curth, U.; Drosten, C.; Sauerhering, L.; Becker, S.; Rox, K.; Hilgenfeld, R., Crystal structure of SARS-CoV-2 main protease provides a basis for design of improved alpha-ketoamide inhibitors. Science 2020, 368, 409-412.

Zhang, C. H.; Stone, E. A.; Deshmukh, M.; Ippolito, J. A.; Ghahremanpour, M. M.; Tirado-Rives, J.; Spasov, K. A.; Zhang, S.; Takeo, Y.; Kudalkar, S. N.; Liang, Z.; Isaacs, F.; Lindenbach, B.; Miller, S. J.; Anderson, K. S.; Jorgensen, W. L. Potent Noncovalent Inhibitors of the Main Protease of SARS-CoV-2 from Molecular Sculpting of the Drug Perampanel Guided by Free Energy Perturbation Calculations. ACS Cent. Sci. 2021, 7, 467-475. https://doi.org/10.1021/acscentsci.1c00039.

Zhu, L.; George, S.; Schmidt, M. F.; Al-Gharabli, S. I.; Rademann, J.; Hilgenfeld, R. Peptide Aldehyde Inhibitors Challenge the Substrate Specificity of the SARS-Coronavirus Main Protease. Antiviral Res.2011, $92(2), 204-212$.

\section{Figures}




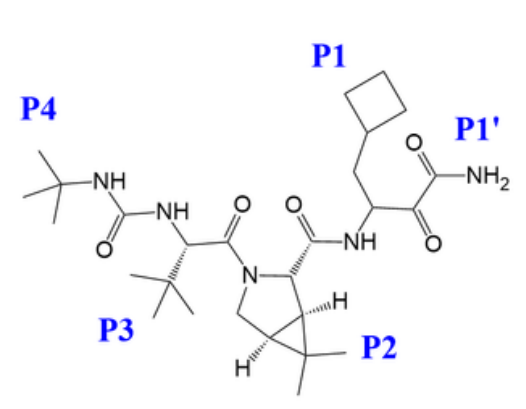

Boceprevir

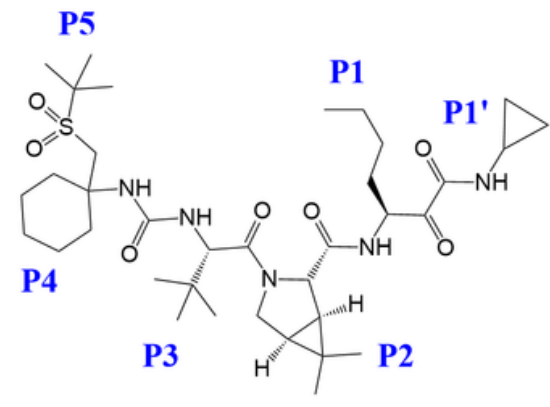

Narlaprevir



GC-376

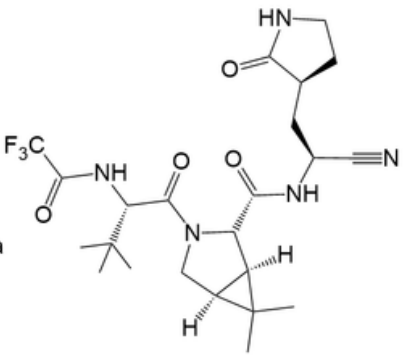

PF-07321332

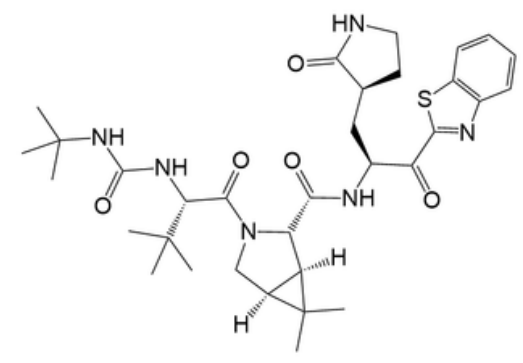

BBH-1



BBH-2

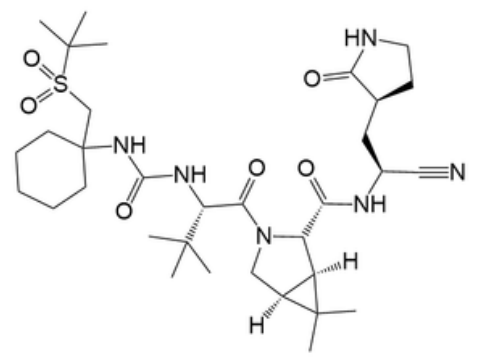

NBH-2

Figure 1

Chemical structures of protease inhibitors.

Figure 2

Joint X-ray/neutron crystal structure of deuterated SARS-CoV-2 Mpro with BBH-1.

a) Electron and b) nuclear density for $\mathrm{BBH}-1 \mathrm{c}$ ) covalently bound in the $\mathrm{M}^{\text {pro }}$ active site. d) Direct and water-mediated hydrogen bond interactions between $\mathrm{BBH}-1$ and $\mathrm{M}^{\text {pro }}$. Protein homodimer represented with one protomer as white surface and the other as salmon cartoon. Electron (pink mesh) and nuclear (purple mesh) density of BBH-1 (cyan ball and sticks) contoured to $1 \sigma$. Hydrogen bonds are represented as black dashes with distances in angstroms $(\AA)$. Deuterium atoms are colored in light orange.

Figure 3

Direct observation of $\mathrm{BBH}-1$ electrostatic interactions with $\mathrm{M}^{\text {pro }}$ determined by neutron crystallography 
a) Cys145 reacts with the keto-benzothiazole warhead of $\mathrm{BBH}-1$ to form a covalent hemithioketal group with an alkoxy anion directed towards the oxyanion hole and hydrogen bonding to an accompanied $\mathrm{D}_{2} \mathrm{O}$ molecule. b) Hydrogen bond network involved with the $\mathrm{P} 1 \mathrm{~g}$-lactam of $\mathrm{BBH}-1$ in the $\mathrm{M}^{\text {pro }} \mathrm{S} 1$ pocket. $\mathrm{c}$ ) The catalytic His41 in M $\mathrm{M}^{\text {pro/BBH}}-1$ is singly protonated on $\mathrm{N} \delta 1$ and forms a $\mathrm{C}-\mathrm{D} \cdots \mathrm{N}$ interaction (orange dashes) with His164. d) The P1' benzothiazole group of BBH-1 sterically swings His41 from its position in the ligand-free $\mathrm{XN}$ structure of $\mathrm{M}^{\text {pro }}(7 \mathrm{JUN})$ and evicts the catalytic water molecule. Protonation states of His41 and His 164 change from doubly protonated to singly protonated. BBH-1 as cyan ball and sticks. Ligand-free $\mathrm{M}^{\text {pro }}$ colored in salmon. Neutron 2Fo-Fc map (purple mesh) contoured at $1.0 \sigma$. Omit nuclear Fo-Fc for D atoms on His41 and His164 are shown as green mesh contoured at 4 and $2.8 \sigma$ respectively. Hydrogen bonds represented as black dashes. Distance are given in angstroms $(\AA)$. Deuterium atoms are colored in light orange.

\section{Figure 4}

Room-temperature X-ray crystal structures of $\mathrm{M}^{\mathrm{pro}}$ in complex with nitrile-warhead inhibitors $\mathrm{BBH}-2, \mathrm{NBH}-$ 2, and PF-037321332

a-c) Inhibitors BBH-2, NBH-2, and PF-037321332 bind to the active site of $\mathrm{M}^{\text {pro }}$ and form a covalent thioimidate with Cys145. Polder omit maps of inhibitor atoms (blue mesh) contoured to $3 \sigma$. d-f) Hydrogen bonds between inhibitors and $\mathrm{M}^{\mathrm{pro}}$ are shown as black dashes with distances in angstroms $(\AA)$.

\section{Figure 5}

\section{Active site structural plasticity of $\mathrm{M}^{\text {pro }}$ bound to nitrile-war head inhibitors}

Comparison of ligand-free $\mathrm{M}^{\text {pro }}$ (7JUN, white cartoon) with the BBH-2, NBH-2, and PF-037321332 shows significant structural shifts in protein subsites S2, S4, and S5 responsible for binding to inhibitor P2, P4, and P5 moieties respectively. Distances are given in angstroms $(\AA)$. Superposition is calculated by the least-square-fitting of $\mathrm{Ca}$ atoms.

\section{Supplementary Files}


This is a list of supplementary files associated with this preprint. Click to download.

- SupportingInfover11.pdf

- 7TDUD1000262114valreportfullannotateP1.pdf

- 7SI9D1000260323valreportfullannotateP1.pdf

- 7TFRD1000262185valreportfullannotateP1.pdf

- 7TEHD1000262162valreportfullannotateP1.pdf 